\title{
DETERMINATION OF SEISMIC EARTH PRESSURES ON RETAINING WALLS THROUGH FINITE ELEMENT ANALYSIS
}

\author{
A Thesis \\ presented to \\ the Faculty of California Polytechnic State University, \\ San Luis Obispo
}

\author{
In Partial Fulfillment \\ of the Requirements for the Degree \\ Master of Science in Civil Engineering
}

by

Michael Joseph Iannelli

December 2016 
(C) 2016

Michael Joseph Iannelli

ALL RIGHTS RESERVED 


\section{COMMITTEE MEMBERSHIP}

TITLE: Determination of Seismic Earth Pressures on Retaining Walls through Finite Element

Analysis

AUTHOR: $\quad$ Michael Joseph Iannelli

DATE SUBMITTED: December 2016

COMMITTEE CHAIR: $\quad$ Dr. Robb Moss, Ph.D., P.E.

Associate Professor of Civil Engineering

COMMITEE MEMBER: $\quad$ Dr. Eric Kasper, Ph.D., P.E.

Professor of Civil Engineering

COMMITTE MEMBER: $\quad$ Dr. Radu Popescu, Ph.D., P.E.

Lecturer, Architectural Engineering 


\begin{abstract}
Determination of Seismic Earth Pressures on Retaining Walls through Finite Element Analysis

Michael Joseph Iannelli
\end{abstract}

Seismic pressures on displacing or rigid retaining or basement walls have been derived based on the original work of Mononobe and Okabe, who used a shake table to calculate dynamic pressures of displacing retaining walls existing in cohesionless soils. Since this original work was done over eighty years ago, the results of Mononobe and Okabe, colloquially known as M-O theory, have been applied to different conditions, including non-displacing basement walls, as well as changes in soil properties. Since the original work of M-O, there have been numerous studies completed to verify the accuracy of the original calculation, most notably the work of Seed and Whitman (1970), Wood (1973), Sitar (Various), and Ostadan (2005). This has resulted in varying opinions for the accuracy of M-O theory, whether it is grossly unconservative or conservative, as well as its effectiveness for situations where the wall does not displace enough to engage active soil conditions.

This study examines (3) different wall cases, a cantilever retaining wall, gravity retaining wall, and rigid basement wall, through an implcit finite element analysis, under simple sinusoidal boundary accelerations. The soil is modeled using the Drucker-Prager model for elastic-plastic properties. The dynamic pressure increment is observed for different driving frequencies, with the anticipation that an in-phase and out of phase response between the soil and structure will be achieved, resulting in both lower and higher than M-O pressure values.

Keywords: Mononobe-Okabe, Soil-structure Interaction, retaining walls, dynamic pressure increment, finite element analysis, ABAQUS, Drucker-Prager 


\section{ACKNOWLEDGMENTS}

There are many I would like to thank for their contributions and help towards accomplishing my goals. Any work involving long hours in front of the computer screen is always made easier with company and encouragement from friends and colleagues. I would like to thank all of those who endured the hours with me in the grad lab, and put up with my antics for months on end. I would like to thank Dr. Garrett Hall and Dr. Eric Kasper for their help in discussion with me and my countless questions regarding ABAQUS and optimization of my models. It was both a valuable learning and humbling experience for me to have the help of such knowledgeable sources. Additionally, I would like to thank Dr. Radu Popescu for his help and expertise with soil modeling through finite element analysis and explanations that clarified essential concepts throughout my work.

I would like to also extend a thank you to my advisor, Dr. Moss, for lending his background of soil mechanics knowledge and keeping my direction of research on track during this entire process. Additionally, his ability to motivate me to continue forward with my research through multiple adverse times has been memorable and a reflective experience in the very least, and no doubt an experience I will take with me long after my days on campus have passed.

Finally, I would like to thank the support I've received from my roommates, my parents, and my girlfriend. The endless positive feedback and words of encouragement I have received day in and day out were many times, the only thing I needed to keep a level head and take everything one day at a time. Thank you for always helping me to move forward. 


\section{TABLE OF CONTENTS}

Page

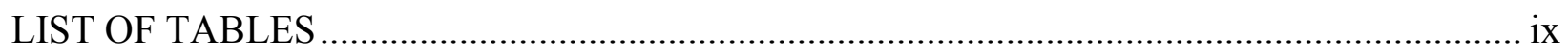

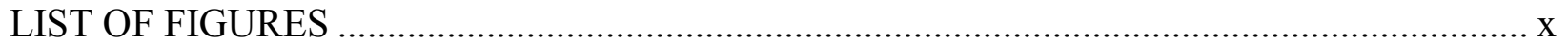

CHAPTER

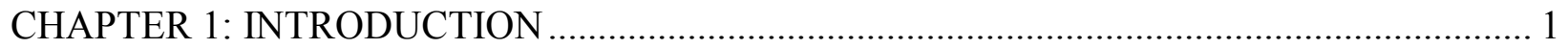

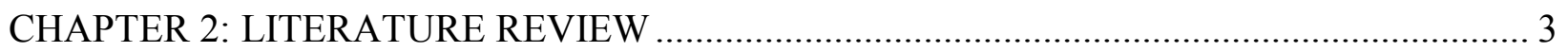

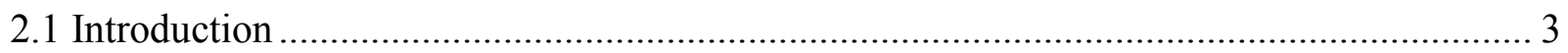

2.2 Initial Theory of Design (Mononobe-Okabe) …………................................................... 3

2.3 Seed and Whitman (1970) ........................................................................................... 5

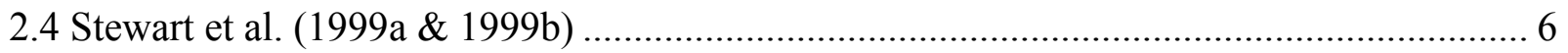

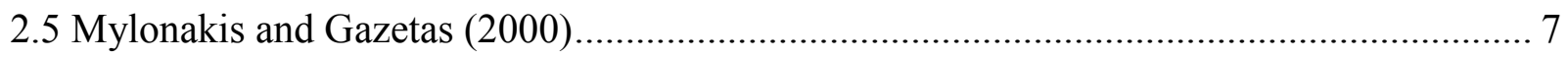

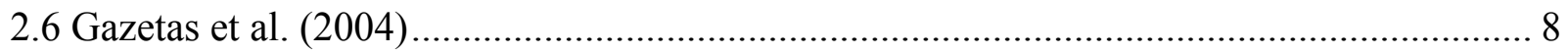

2.7 Ostadan (2005) ......................................................................................................... 9

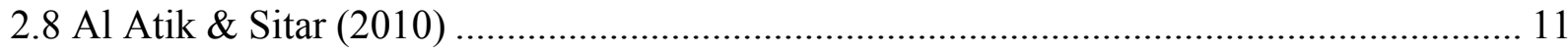

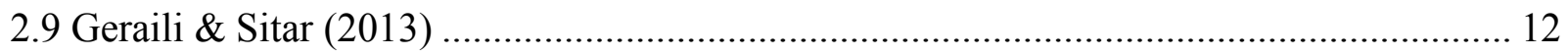

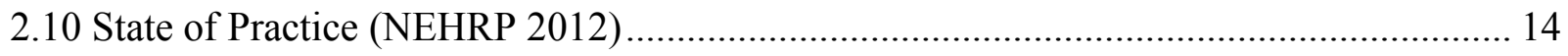

2.11 Brandenberg, Mylonakis, \& Stewart (2015) ………………................................... 15

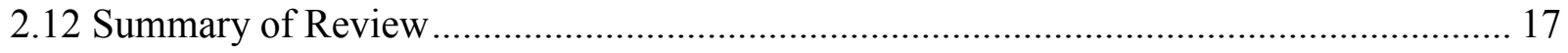

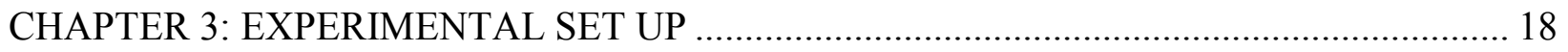




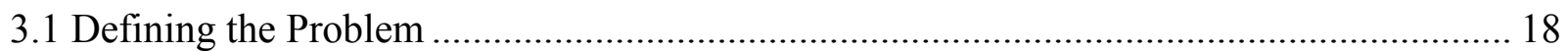

3.2 Basis of Finite Element Method Used in Model Set-Up.................................................. 19

3.3 Summary of Model Software and Parameters................................................................ 19

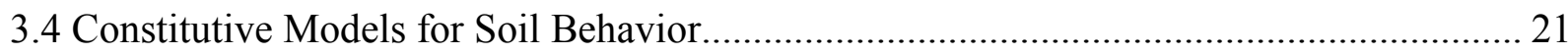

3.5 Summary of General Drucker-Prager \& extended Drucker-Prager Models ........................ 21

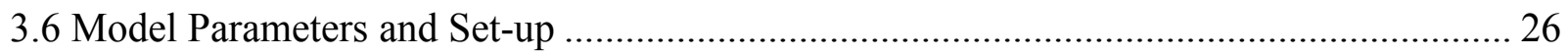

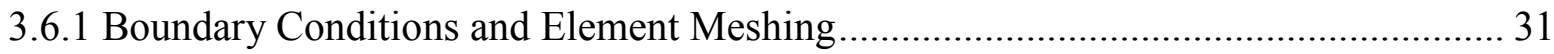

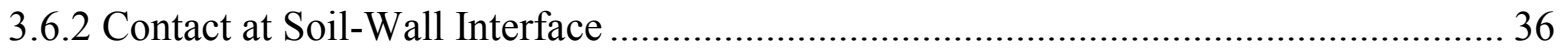

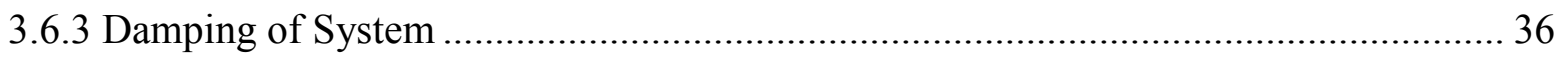

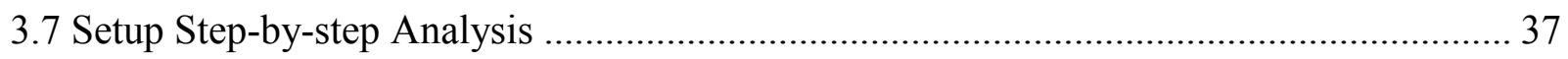

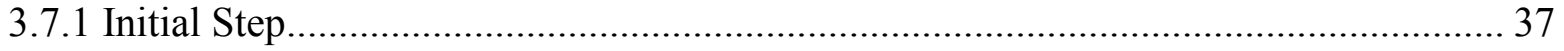

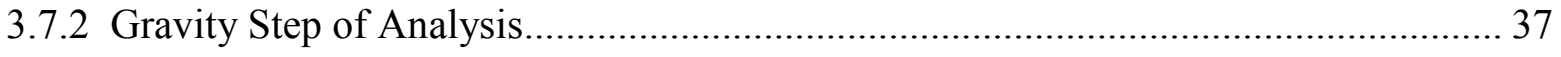

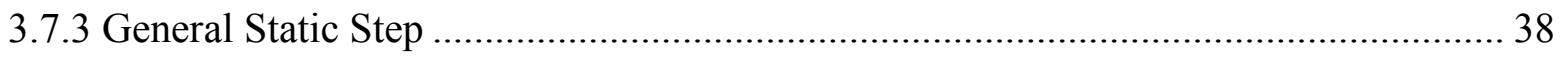

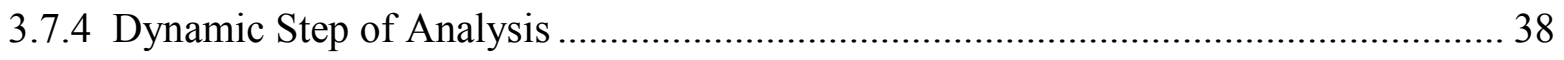

3.7.5 Driving Frequencies used in Acceleration Boundary Condition.................................. 39

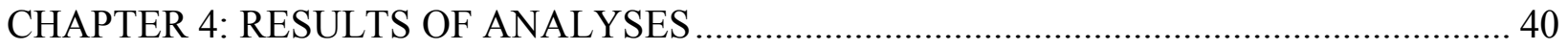

4.1 Running of Analysis and Exporting Results .................................................................... 40

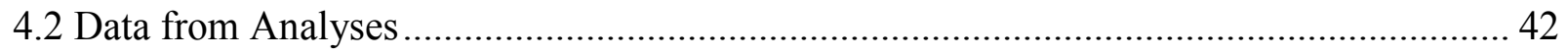

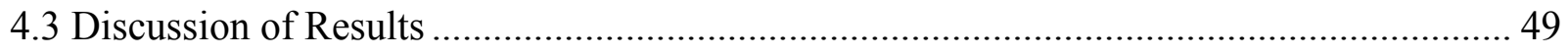

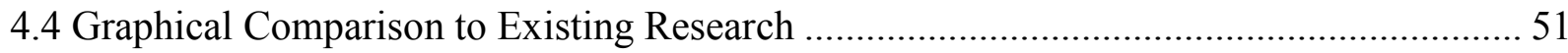




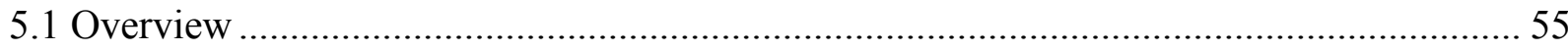

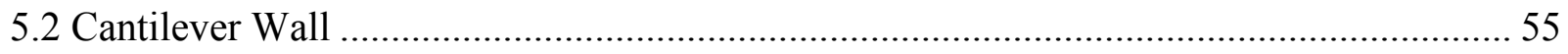

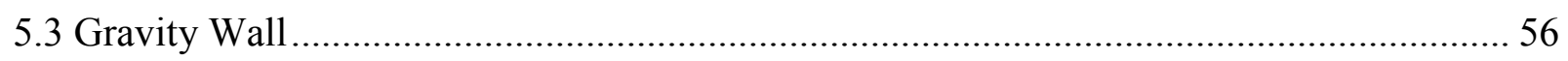

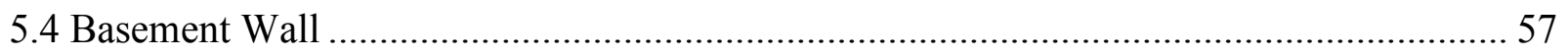

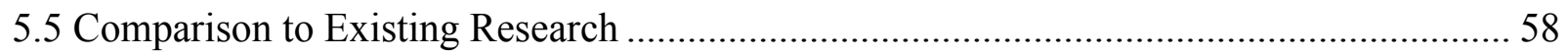

5.6 Recommendations for Future State of Practice …………............................................. 59

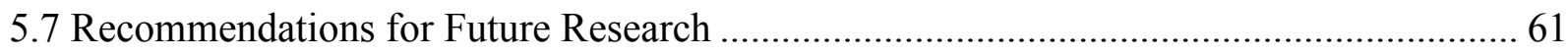

5.7.1 Variations in Ground motion \& Boundary Conditions ................................................ 61

5.8 Summarization of Study \& Accomplishment of Goals..................................................... 62

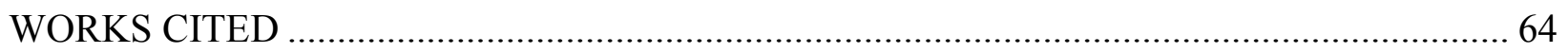




\section{LIST OF TABLES}

Table

Page

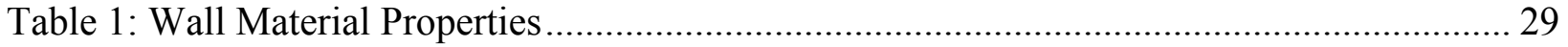

Table 2: Soil Material Properties ............................................................................................ 30 


\section{LIST OF FIGURES}

Figure

Page

Figure 1: Mononobe \& Mastuso Shake Table Schematic (1929). 4

Figure 2: Effects of Period Lengthening and Foundation Damping on Design Spectral acceleration in General Case (a) and for Specific Site Effects (b) Stewart a et al. (1999) ............ 7 Figure 3: Results of Simplified method by Ostadan (2005) compared to M-O method and Wood (1973) 10

Figure 4: Maximum Pressure Coefficient, $\mathrm{K}_{\mathrm{ae}}$ vs. PGA for displacing Retaining Wall, from Geraili \& Sitar (2013) 13

Figure 5: a) Instrumentation plan of building subjected to Whittier Earthquake 1987, b) acceleration time histories of free field response, $u g$, and foundation response, $u$ fndn, and

c) calculated transfer functions (NEHRP 2012) 14

Figure 6: Results of Seismic Earth Pressure Vs. Depth Computed using Simplified Approach in Comparison with Ostadan (2005) and Sitar (2010), (Brandenberg et al. 2015) Ultimately, Brandenberg et al. (2015) makes the case for both observations regarding MO method...... 16

Figure 7: Comparison of Drucker-Prager and Mohr-Coulomb Yield Surfaces (from globalspec.com)

Figure 8: Linear Drucker-Prager Yield Surface with Hardening in the p-t Plane (Adapted from ABAQUS User's Guide, 2014) 24

Figure 9: Hardening Behavior of Soil (Adapted from Helwany, 2007) Originally Adapted from ABAQUS (2002) 25

Figure 10: Wall dimensions for Cantilever Wall Model 27

Figure 11: Wall dimensions for Gravity Wall Model 28 
Figure 12: Wall dimensions for Basement Wall Model

Figure 13: Drucker-Prager Hardening Curve For Constitutive Soil Model .............................. 31

Figure 14: Initial Mesh of Cantilever Wall................................................................... 34

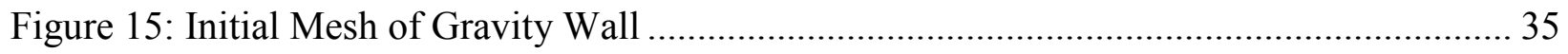

Figure 16: Initial Mesh of Basement Wall.................................................................... 35

Figure 17: Dynamic Pressure Increment Vs. Depth For Cantilever Retaining Wall at

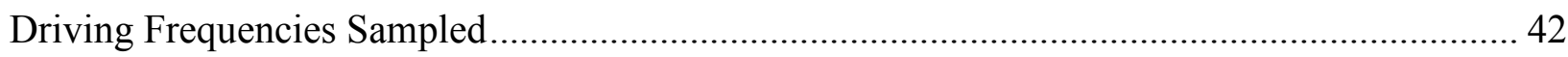

Figure 18: Dynamic Pressure Increment Vs. Depth For Gravity Retaining Wall at Driving

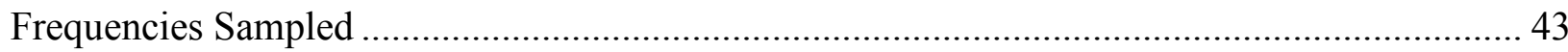

Figure 19: Dynamic Pressure Increment Vs. Depth For Basement Retaining Wall at

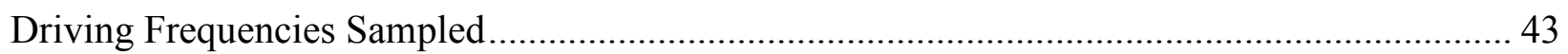

Figure 20: Cantilever Wall Maximum Pressures Observed at Each Frequency Sampled,

Depth vs. Pressure, compared to At Rest \& Static Active Conditions ..................................... 44

Figure 21: Gravity Wall Maximum Pressures Observed at Each Frequency Sampled, Depth

vs. Pressure, compared to At Rest \& Static Active Conditions ............................................. 44

Figure 22: Basement Wall Maximum Pressures Observed at Each Frequency Sampled,

Depth vs. Pressure, compared to At Rest Conditions ....................................................... 45

Figure 23: Color Contour of Maximum Horizontal Accelerations at Cantilever Wall at 1

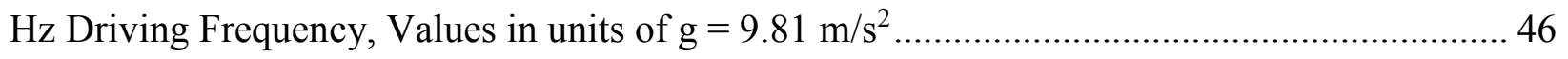

Figure 24: Color Contour of Maximum Horizontal Accelerations at Gravity Wall at $1 \mathrm{~Hz}$

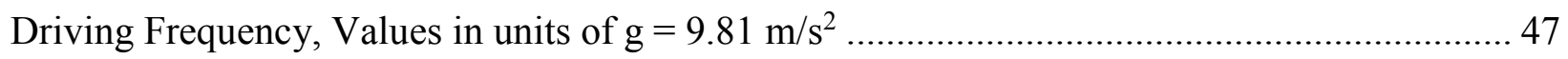

Figure 25: Basement Color Contour of Maximum Horizontal Accelerations at Basement

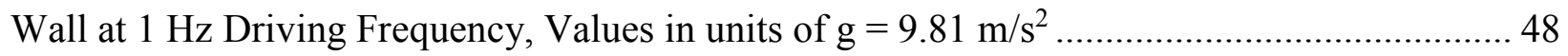


Figure 26: Color Contour of Minimum Horizontal Accelerations at Cantilever Wall at 20

Hz Driving Frequency (Other Cases Similar), Values in units of $g=9.81 \mathrm{~m} / \mathrm{s}^{2}$

Figure 27: Comparison of Al Atik \& Sitar (2009) \& Brandenberg et al. (2015) with

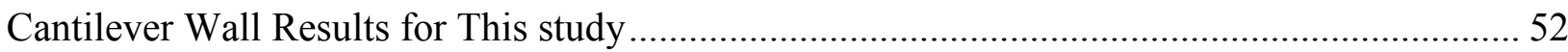

Figure 28: Comparison of Al Atik \& Sitar (2009) \& Brandenberg et al. (2015) with

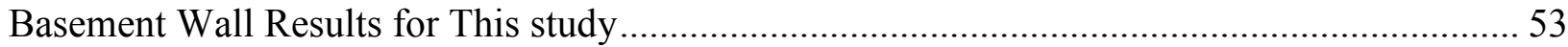




\section{CHAPTER 1 INTRODUCTION}

\subsection{Background}

Seismic design of new infrastructure as well as evaluation of existing structural components very often includes those founded upon, or proportionally close to a retaining or basement wall. As the seismic design of any above ground or below ground structure in an area prone to earthquakes is critical, so is the foundation that it rests upon. However, there have been many recent, well-documented seismic events, with critical structural failures or weaknesses observed, with little to no damage of retaining walls or basement walls subjected to the same conditions. This brings up the issue of whether all of these structures are inherently over designed, or simply have not been subjected to the type of seismic force that would lead to partial or complete failure.

Lateral earth pressures were originally calculated using the methods of Coloumb (1776) where an active wedge was mobilized in order to generate an active pressure, the value of which could be computed using geometric properties and basic equations of equilibrium. Lateral seismic pressures for retaining walls originated using this approach, where the work of Mononobe (1926) and Okabe and Mastuso (1929) resulted in Mononobe-Okabe (M-O) theory for retaining walls. This theory used primitive shake table experiments, described in greater detail in the following sections, to calculate seismic earth pressures for displacing retaining walls founded in cohesionless soils, i.e. sand. This theory has since been applied to numerous different wall conditions, and apart from modifications to the original coefficients by Seed \& Whitman (1970), has remained largely unchanged since its inception.

One of the issues associated with M-O theory has been the level of conservativeness when designing a wall system. This is apparent in the large number of retaining walls subjected to seismic ground motions that have not failed or been deemed structurally deficient, even those not 
originally designed for seismic loading. Some notable cases of this are described in the following sections as well. Additionally, when using $\mathrm{M}-\mathrm{O}$ theory in practice, current computational programs such as RetainPro ${ }^{\circ}$ default to applying a suggested acceleration value of 0.3 times the peak ground acceleration. Because of these issues with M-O theory, multiple studies have been undertaken to evaluate its true accuracy as a method of seismic design for retaining walls.

This study is concerned with both the accuracy of M-O theory, as well as explaining the work of Ostadan (2005), and Sitar et al. (2009 \& 2013). Both have diverging opinions regarding $\mathrm{M}-\mathrm{O}$ theory as being over and under conservative, respectively. We present an analysis of three major wall types, an unrestrained cantilever and gravity retaining wall, as well as a rigid basement wall, to explain both sides of this issue. Our analysis consists of compiling a finite element analysis (FEA) of each wall through the Program ABAQUS CAE, subjected to sinusoidal boundary accelerations at different frequencies. The hope of this is to capture different snapshots of the walls responding in phase with the surrounding soil, producing lower than M-O pressures on them, as well as out of phase responses, producing higher than M-O pressures. Because this study deals intensively with soil-structure interaction (SSI), it is critical to model the elastic plastic properties of the soil and contact with the structure accurately in the FEA. The results and conclusions of this analysis, in chapters 4 and 5 respectively, will show the importance that SSI plays in determining seismic pressures for retaining walls with regards to $\mathrm{M}-\mathrm{O}$ theory, and under what conditions in phase, and out of phase responses can be expected. 


\section{CHAPTER 2 LITERATURE REVIEW}

\subsection{Introduction}

Soil structure interaction is the term used to define how during a seismic event, effects between the soil and structure produce forces that are not accounted for with a typical fixed base analysis approach. Soil structure interaction can be grouped into two different mechanisms, inertial and kinematic which affect two different types of structural systems. Inertial interactions are the structure's own vibration that induces base shear, and with it, a displacement of the foundation relative to the ground. These effects can be described using frequency dependent transfer functions. Inertial interaction dominates structural systems with relatively high inertia, such as a tall building with a relatively shallow foundation. (Stewart, Seed, Fenves, 1999a \& b) Kinematic interaction is due to foundation motions differing from the surrounding free field ground motion of the soil around the structure. In contrast to inertial interactions, kinematic interactions occur where there is relatively little inertia of the structure compared to the surrounding soil medium, as is the case with structural systems deeply embedded in the soil, or with a deep foundation. Impedance functions can be used to analyze kinematic interaction and are found in Luco and Roesset et al. (1980), but significant effects for embedded foundations, non-circular foundations, flexibility of the foundation and non-uniform soil profiles need to be taken into account to ensure accuracy of the function. (Stewart et al. 1999a).

\subsection{Initial Theory of Design (Mononobe-Okabe)}

Seismic retaining wall design has been based on the work carried out by Mononobe and Matsuo (1929), and Okabe (1926). The experiments were carried out using a shake table, the schematic of which is depicted in figure 1. M-O theory utilizes a Mohr-Coulomb failure wedge (Coulomb 


\section{Elevation.}
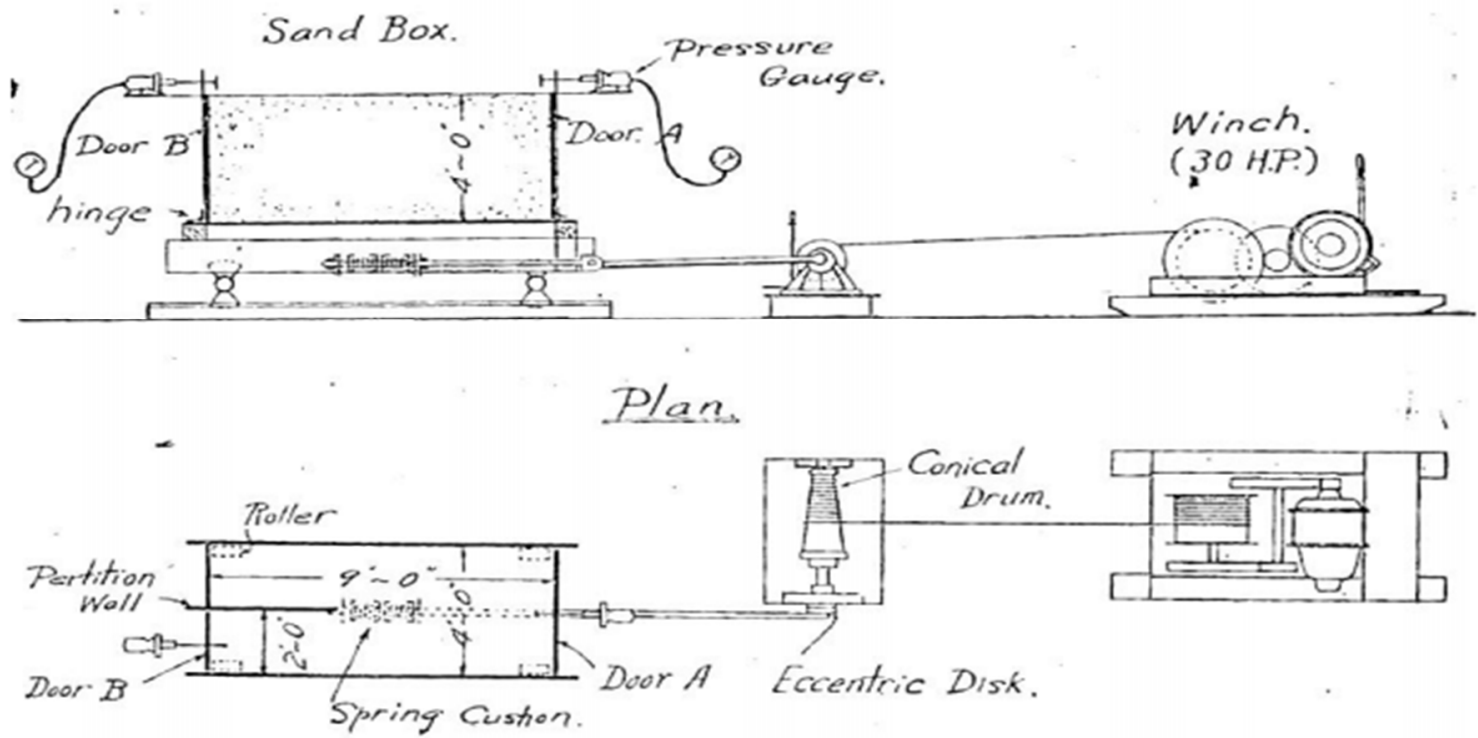

Figure 1: Mononobe \& Mastuso Shake Table Schematic (1929)

1776) to mobilize active earth pressures during an earthquake. Additional assumptions included in the theory are that the soil behind the wall consists of a cohesionless, granular backfill, with a constant internal friction angle, and that the wall is sufficiently long enough to neglect end effects.

The resulting pressures on the retaining wall are derived using static force equilibrium equations.

The dynamic active pressure, $\mathrm{P}_{\mathrm{ae}}$, can then be calculated as follows (Sitar 2013):

$P_{a e}=\frac{1}{2} * \gamma H^{2}\left(1-k_{v}\right) K_{a e}$

Where $\mathrm{K}_{\mathrm{ae}}$ can be calculated as follows:

$K_{a e}=\frac{\cos ^{2}(\varphi-\psi-\beta)}{\cos \psi \cos ^{2} \beta \cos (\delta+\beta+\psi)\left[1+\sqrt{\frac{\sin (\varphi+\beta) \sin (\varphi-\psi-i)}{\cos (\delta+\beta+\psi) \cos (i-\beta)}}\right]^{2}}$ 
Where:

$H=$ height of wall

$k v=$ vertical acceleration coefficient pertaining to soil wedge

$k h=$ horizontal acceleration coefficient pertaining to soil wedge

$\psi=\tan ^{-1}\left(\mathrm{k}_{\mathrm{h}} /\left(1-\mathrm{k}_{\mathrm{v}}\right)\right)$

$\gamma=$ unit weight of backfill

$\varphi=$ friction angle of backfill

$\delta=$ friction angle at backfill/wall interface

$\beta=$ angle between inner wall face and vertical

$i=$ slope of backfill measured from horizontal

M-O theory has since been applied to a myriad of different retaining wall problems with varying soil properties, the original method having been modified for specific additional parameters not originally accounted for.

2.3 Seed and Whitman (1970)

M-O theory as used today has been modified to more accurately represent seismic earth pressures on retaining walls over a wider array of wall and soil back fill conditions. Seed and Whitman (1970) proposed modifications to M-O theory based upon their parametric study performed. One of the principal changes was to divide the pressure on the wall into a static force, as well as a dynamic force mobilized during a seismic event. The resulting, modified M-O equations, as referenced from Sitar et al. 2013 are represented as follows:

$$
\begin{aligned}
& P_{a e}=P_{a}+\Delta P_{a e} \ldots \\
& K_{a e}=K_{a}+\Delta K_{a e} .
\end{aligned}
$$

Where the changes in dynamic pressure are calculated as:

$$
\begin{aligned}
& \Delta K_{a e} \cong \frac{3}{4} k_{h} \ldots \ldots \ldots \\
& \Delta P_{a e}=\frac{1}{2} \gamma H^{2} \frac{3}{4} k_{h} .
\end{aligned}
$$


Seed and Whitman (1970) recommended that the resultant pressure due to both seismic and static forces be moved from the initial value calculated by Mononobe (1929) of $1 / 3$ the height of the wall above the base to a value approximately 0.6 of the total height of the wall above the base of the backfill retained material. Seed and Whitman (1970) surmised that because peak ground acceleration does not occur for the full duration of the event, but rather an arbitrarily short time that a value of 0.85 times the PGA would be adequate for the seismic design of retaining walls. With these added developments, Seed and Whitman (1970) recommended that "many walls adequately designed for static earth pressures will automatically have the capacity to withstand earthquake ground motions of substantial magnitudes and in many cases, special seismic earth pressure provisions may not be needed." Sitar et al. (2013) comments on this as "the basis of this recommendation is not given and cannot be traced to any published information."

2.4 Stewart et al. (1999a \& 1999b)

Stewart et al. (1999a \& 1999b) takes a look into the inertial SSI effects on structures, and quantifies them by both analytical methods (a), and by empirical research as well (b). The focus of the reports was to evaluate and better strengthen the link between strong motions transmitted to structures from the free field, and the structural response to these motions. Inertial effects of SSI are quantified commonly in terms of period lengthening ratio ( $\check{\mathrm{T}} / \mathrm{T})$, in addition to effective damping. Stewart et al. (1999a) identifies that a structure represented as a single degree of freedom model with a fundamental period $\mathrm{T}$, and damping ratio $\xi$ can have accurately predicted maximum seismic induced deformations, i.e. a flexible base parametrized model. It was also noted that the most critical controlling factor in period lengthening of a structure under seismic loading is the ratio of soil to structure stiffness. $(1 / \sigma)$. In effect, with a loose soil and stiff structure, the period lengthening due to the inclusion of a flexible base model can cause a resonant frequency of the 
structure and the ground motion that would not be calculated using a fixed base approach. Figure 2 referenced from Stewart et al. (1999a) shows the changes in spectral acceleration as they relate to period lengthening ratio, using both a fixed base prodecure, and flexible base procedure (which includes soil-structure interaction effects).

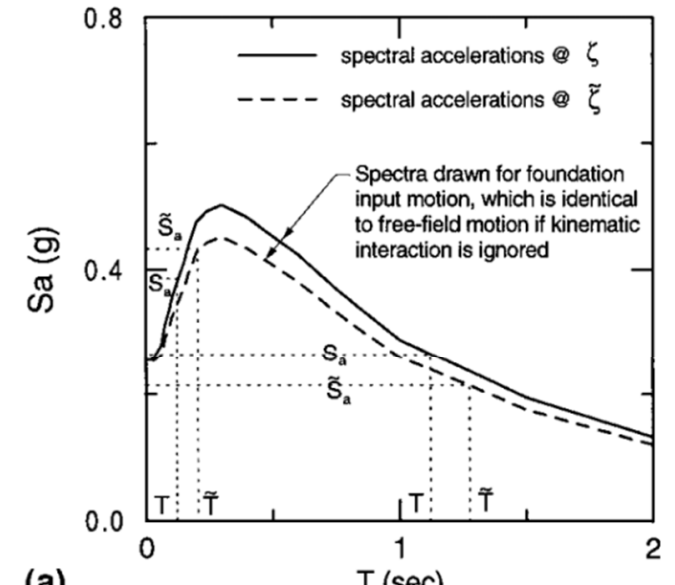

(a) $\mathrm{T}(\mathrm{sec})$

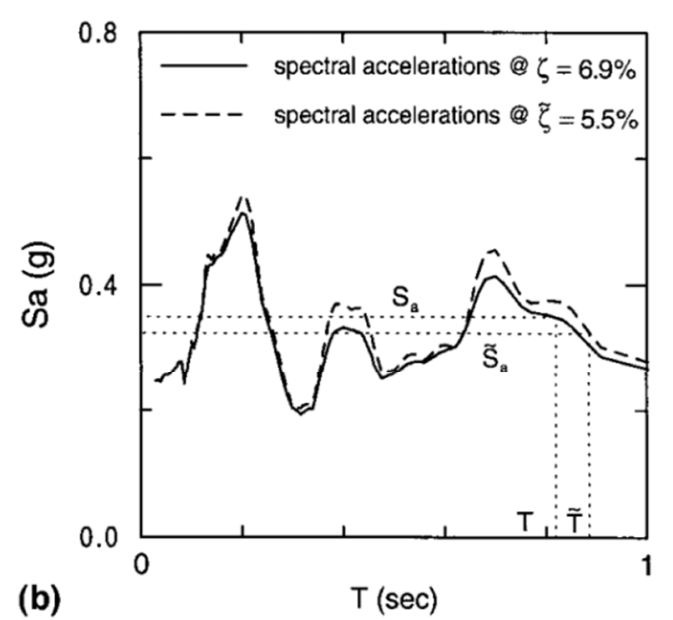

(b)

$\tilde{\mathrm{T}}, \tilde{\zeta}=$ Flexible-base period, damping ratio

$\mathrm{T}, \zeta=$ Fixed-base period, damping ratio

Figure 2: Effects of Period Lengthening and Foundation Damping on Design Spectral acceleration in General Case (a) and for Specific Site Effects (b) Stewart et al. (1999a)

Stewart et al. (1999b) reiterated the importance of soil to structure stiffness in comparison of 57 different sites of structures with various foundation conditions, both embedded and surface types. It was noted that the majority of other factors, including structural lateral force resisting system, foundation shape and type, had minimal effects on period lengthening ratio.

2.5 Mylonakis and Gazetas (2000)

Mylonakis and Gazetas (2000) further investigated the effects of SSI in their paper "Soil Structure Interaction, Beneficial or Detrimental?". They commented that ignoring SSI effects has traditionally been observed as beneficial for seismic code previsions as apparent in ATC-3 and 
NEHRP-97. The cause of this as described by Mylonakis and Gazetas (2000) was due to oversimplifications in the code previsions, including:

- acceleration design spectra decreasing monotonically with increasing structural period

- response modification coefficients remaining constant or increasing with increasing structural period

- foundation impedance values derived assuming a homogenous half-space, over predicting the damping of structures on actual soil profiles.

It had previously been shown by Newmark and Hall (1973) that due to ductility demand imposed on an elastoplastic structure decreasing with an increasing structural period that ignoring SSI effects would be inherently beneficial or conservative in the design. However, Mylonakis and Gazetas (2000) go on to reference Miranda and Bertero (1994) that indicate in certain frequency ranges, this trend may reverse, resulting in an increase in ductility demand with increasing structural period. Furthermore, an increase in the fundamental period due to the inclusion of SSI effects may lead to an increased response despite possible increases in damping of the structure. A case study of this phenomenon focused on the Mexico City Earthquake of 1985, where due to a period lengthening of 1 to 2 seconds due to SSI effects, there was widespread damage in 10 to 12 story buildings, designed under the assumption of a fixed base model. While Mylonakis and Gazetas (2000) commented on the detrimental effects of SSI, it was noted that in smaller period structures SSI has less effect on ductility demand compared to longer period structures.

2.6 Gazetas et al. (2004)

A number of case history studies of retaining wall behavior were observed by Gazetas et al. (2004) in their study of retaining walls subjected to short duration, strong excitation ground motions. In the Kobe 1995 earthquake, it was observed that while unreinforced concrete and 
masonry walls were heavily damaged during the Mw 7 event, relatively small damage was reported for reinforced concrete retaining walls. Additionally, geosynthetic reinforced retaining walls also suffered minimal damage during the event, while being subjected to PGA values on the order of 0.8g. In the 1994 Northridge earthquake, another example of conservatism in retaining wall design was observed by Lew et al. (2010) in which many temporary construction walls around the greater Los Angeles area, with heights as large as 25 meters and subjected to PGA values as high as $0.6 \mathrm{~g}$ were observed to have seismic deflections less than $1 \mathrm{~cm}$. Gazetas et al. (2004) references an interesting case during the 1999 Chi Chi Earthquake in Taiwan, where like the Kobe event, reinforced concrete retaining walls and reinforced soil retaining walls performed relatively well, with some notable differences in performance. Instances of reinforced soil (RS) walls with underdesigned vertical reinforcement subjected to the $\mathrm{Mw} 7.6$ event resulted in localized bulging and buckling of the lowest sections of the wall, in a few cases leading to a complete failure.

\subsection{Ostadan (2005)}

Ostadan (2005) described the current M-O approach to design of embedded basement walls as "one of the most absurd methods used in geotechnical practice." Due to the fact that the M-O method and modified method by Seed and Whitman (1970) utilizes large movement of a retaining wall under seismic loading to initiate a sliding wedge behind the wall, and therefore changing the earth pressure from at rest to active conditions, it is therefore not applicable to embedded basement walls or situations where the full active earth pressure is not attained during a seismic event. Ostadan (2005) cites studies by Wood (1973) and Velestos (1994) where the former bases a solution using analytical and finite element techniques off of static, $1 \mathrm{~g}$ loading but neglects to include wave propagation and motion amplification characteristics. The solution of seismic pressures on building walls calculated by Wood (1973) has been applied to many essential 
facilities. Velestos (1994) takes into account wave propagation and motion amplification in solving for seismic pressures, however the analysis is rigorous and cumbersome to apply frequently in practice. Ostadan (2005) also cites that recent observations have since confirmed that seismic soil pressure is caused by interaction of the soil and structure, influenced by dynamic soil and structural properties, as well as the seismic ground motion characteristics. This new insight by Ostadan prompted the United States Nuclear Regulatory Commission (USNRC) to reject the application of $\mathrm{M}-\mathrm{O}$ method as it pertains to critical structures. Ostadan (2005) uses transfer functions to develop a normalized pressure profile for a basement wall with different shear wave velocity profiles, showing that $\mathrm{M}-\mathrm{O}$ method is not conservative enough for design purposes. While basement walls and retaining walls represent two different states of SSI, the former dealing with at-rest earth pressures and the latter with active pressures, Ostadan's main

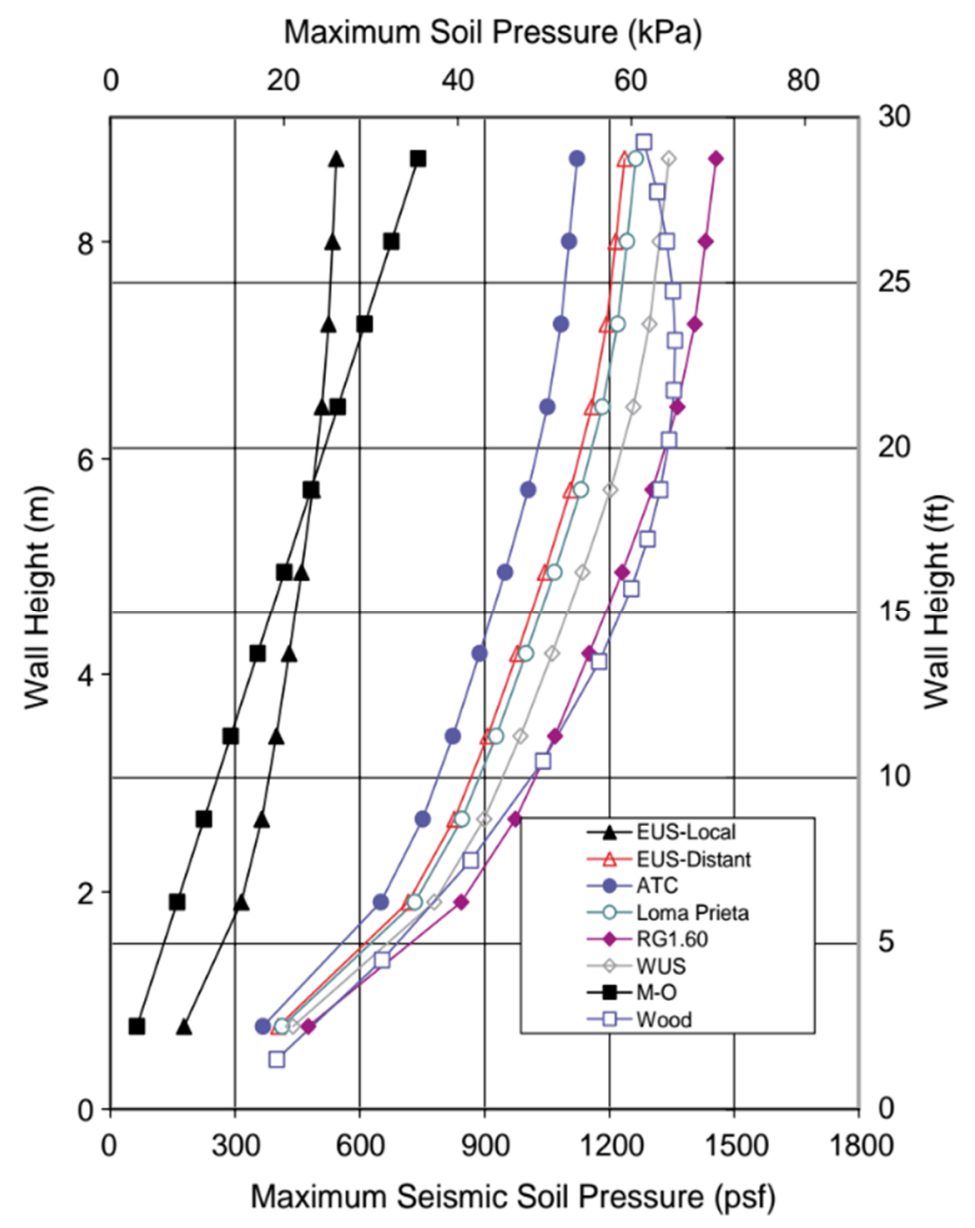

Figure 3: Results of Simplified method by Ostadan (2005) compared to M-O method and Wood (1973)

conclusion of his 2005 study was that the controlling frequency that determines maximum soil pressure is the one that corresponds to the soil column adjacent to the embedded wall of the 
building. Figure 3 shows the pressure vs. depth comparisons for a given $9 \mathrm{~m}$ tall considered in the study, where the simplified method calculated by Ostadan (2005) is compared for several ground motions with the results of Wood (1973) in addition to the traditional M-O method.

\subsection{Al Atik \& Sitar (2010)}

Al Atik and Sitar evaluated the M-O method, quantified in their 2010 report, in which they used centrifuge experiments to validate the compatibility of $\mathrm{M}-\mathrm{O}$ derivations for modern retaining wall design, as well as developing a finite-element model through OpenSees to "study the behavior of retaining walls and backfill under seismic loading." It was noted that the assumptions in M-O theory can ultimately result in a seismic design that is conservative for flexible retaining walls which can mobilize active earth pressures. Because M-O theory couples the analysis of both inertial effects as well as dynamic earth pressures, it is an assumption that they are both occurring simultaneously, i.e. the soil and the wall are completely out of phase. Al Atik \& Sitar noted that their comparisons of these forces show that when the dynamic wall pressures are at or near maximum, inertial effects of the wall are at their near minimum. The converse of this observation also holds true. The inherent conservatism of M-O design is then made apparent; the dynamic wall moment should be calculated by comparing each force to the other with respect to phase, not simply adding them together. Al Atik and Sitar (2010) also comment on the validity of the approach by Seed and Whitman (1970) in that their centrifuge data conflicts with the seismic pressure distribution on the retaining wall. Al Atik and Sitar suggest that the distribution can be approximated by a triangular shape that increases with depth. 


\subsection{Geraili \& Sitar (2013)}

Geraili \& Sitar further quantified the results of their centrifuge experiments in a 2013 study, which involved modeling the centrifuge test structures in a two-dimensional, finite difference model (FLAC), the results of which were then compared to the results of the centrifuge experiments. Sitar noted that in a previous observation, (Sitar et al. 2012) there was little to no observed damage of retaining structures during the 2008 Wenchuan Earthquake in China or the 2010 and 2011 events of Chile and Japan respectively, in which the retaining structures were not designed explicitly for dynamic loading. An initial conclusion of this would be that the nonseismic design of these walls is in fact enough to resist seismic earth pressures without additional design requirements.

Geraili and Sitar observed from the 2010 study centrifuge modeling, that maximum dynamic earth pressures increased with depth and could be reasonably approximated using the same distribution as static earth pressures. This observation was limited to the sizes of walls investigated in the study, approximately 20 to $30 \mathrm{ft}$. The results of Mastuso (1941) and modified by Seed and Whitman (1970) were quantified as being 'performed meticulously and were pioneering in their scope at the time' though Sitar notes that due to limitations in the shake table design used by Mastuso, the conclusions set forth by the original study are inherently limited to the specific conditions which they were originally carried out under As shown in Figure 4, Gerali and Sitar produced a resulting $\mathrm{K}_{\mathrm{ae}}$ of approximately 0.35 of the PGA value, much lower than originally calculated by Seed and Whitman. 


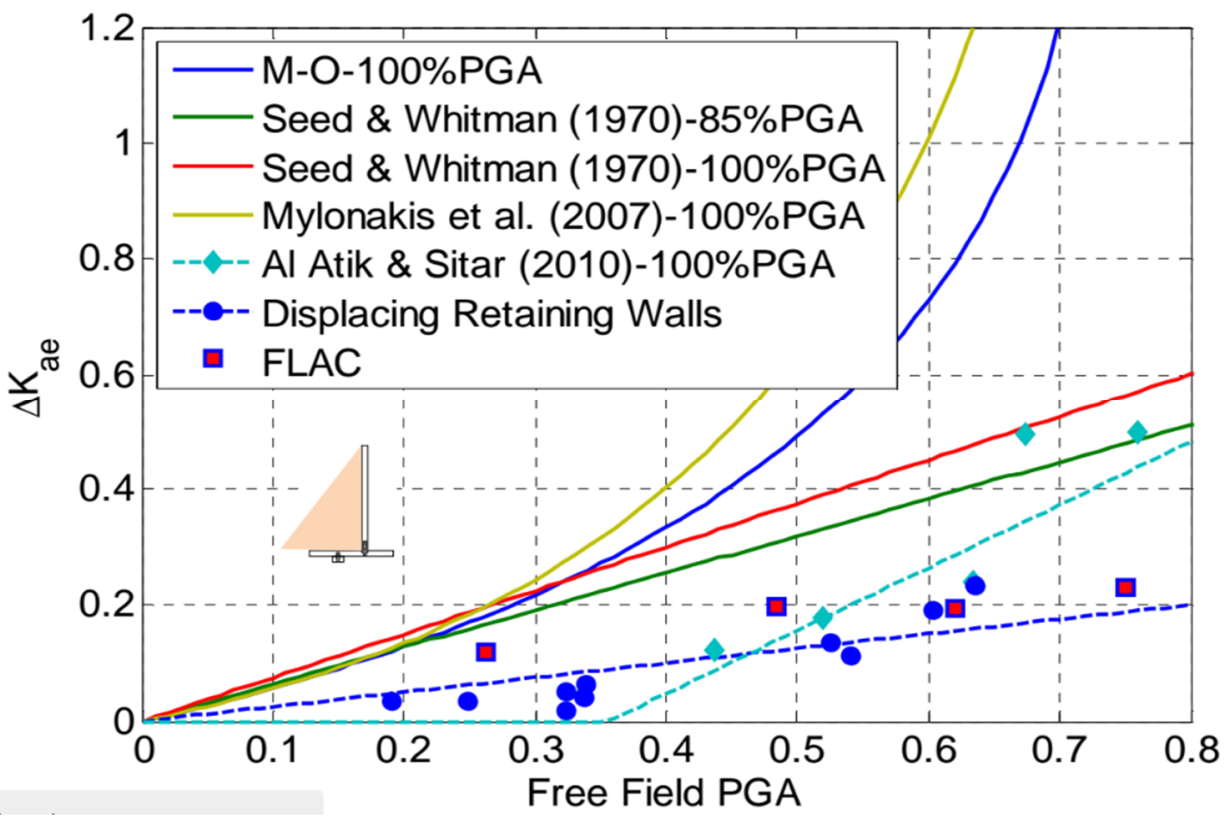

Figure 4: Maximum Pressure Coefficient, $K_{a e}$ vs. PGA for displacing Retaining Wall, from Geraili \& Sitar (2013)

Importantly, Sitar notes that there was also no difference from the seismic earth pressures acting on rigid embedded walls, i.e. basement walls, as opposed to cantilever retaining walls with a fixed base model. He states the estimates of Wood (1973) are inherently much too large for a rigid structure resting on a rigid foundation. Sitar concludes that for current practice purposes, the results of Seed and Whitman, (1970) should be representative of an upper bound of the expected seismic earth pressures on a retaining structure. 


\subsection{State of Practice (NEHRP 2012)}

The NEHRP document 'Soil-Structure Interaction for Building Structures', is a relevant basis of current state of practice regarding SSI. This study notes that for an embedded foundation of a building, with dominant kinematic SSI effects being taken into account, there is a reduced motion at the base of the foundation as opposed to the free field response. The consensus for this occurrence is due to embedment effects and base averaging effects as cited by NEHRP (2012). This finding is backed with a case study using input ground motions and computing transfer functions to illustrate the reduced acceleration time histories of an embedded structure during the 1987 Whittier earthquake, as shown in Figure 5.

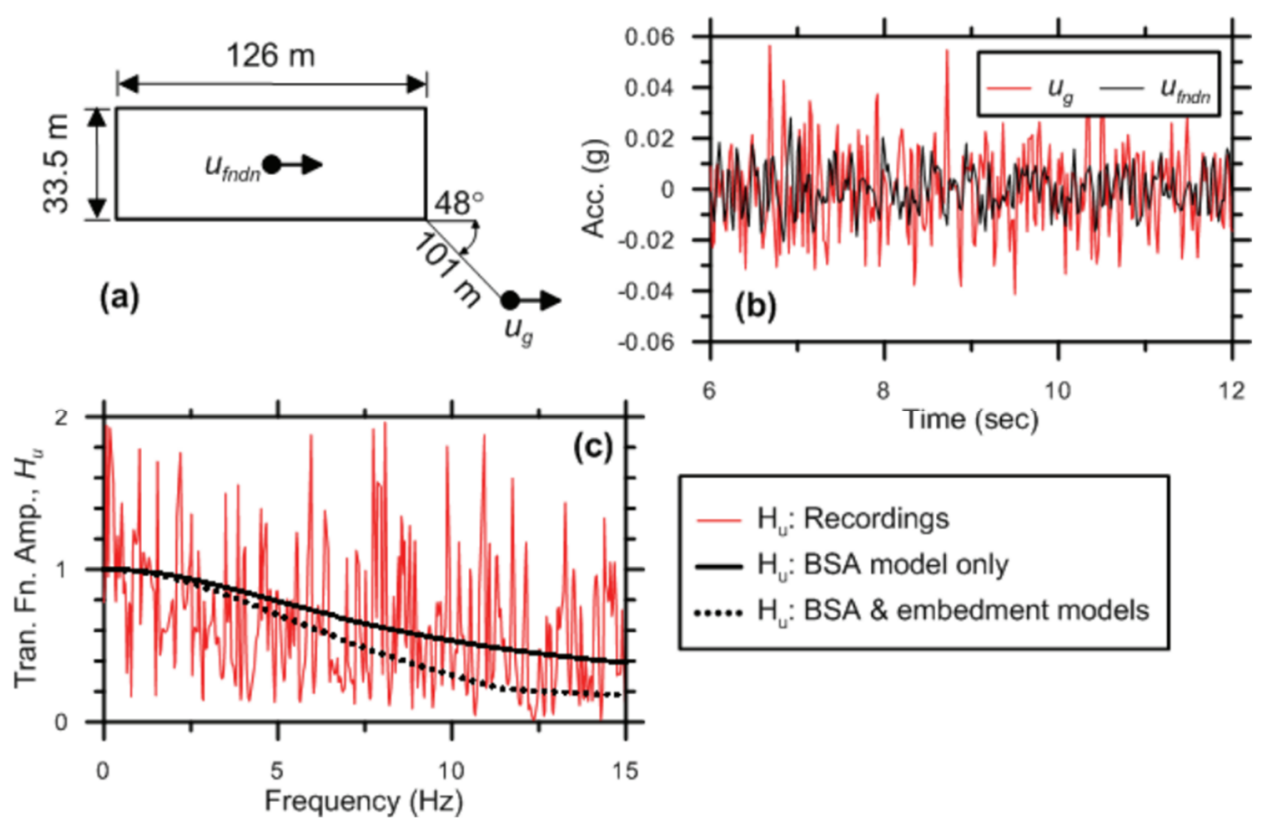

Figure 5 a) Instrumentation plan of building subjected to Whittier Earthquake 1987 , b) acceleration time histories of free field response, ug, and foundation response, $u$ fndn, and c) calculated transfer functions (NEHRP 2012)

NEHRP (2012) summarizes that currently, SSI effects, kinematic or inertial, for any structure on the general order are very commonly neglected for design in practice. Additionally it is noted by NEHRP (2012) that when included, they typically reduce the base shear demands of a 
structure, resulting in a conservative design when not applied at all. ASCE 7-10 does not currently have provisions for the inclusion of kinematic SSI effects, the dominant mode for retaining walls and imbedded structures, although a section is included to address inertial effects, as they apply to period lengthening ratio, of which a simplified procedure for calculating these values is then given in the code. NEHRP (2012) concludes that while decades of research has provided much useful data in the realm of SSI effects, there is still an obvious lag in the inclusion of these effects as they relate to state of practice.

The recommendations for inclusion of SSI effects as stated by NEHRP (2012) include the importance of base slab averaging effects for an equivalent half width of approximately $20 \mathrm{~m}$ or larger. Additionally, embedment effects are noted to be of importance with a depth of approximately 2 stories below the level of adjacent grade.

2.11 Brandenberg, Mylonakis, \& Stewart (2015)

Recently, Brandenberg et al. 2015 quantified seismic earth pressures in an effort to explain the diverging theories described previously by Al Atik and Sitar et al. and Ostadan et al. Limit equilibrium analysis using a failure wedge, the basis for M-O theory, and the modified M-O theory developed by Seed and Whitman et al. was poor for describing the effects of either kinematic or inertial interaction. (Brandenberg et al. 2015). Seismic earth pressures are an effect of the relative displacements of the soil and the wall, which cannot simply be represented by a seismic coefficient and an active wedge, according to Brandenberg et al. 2015. This is true even if the soil wedge exists prior to the ground shaking. It was noted that inertial interactions can induce large displacements in a structure with a large mass, due to the base shear of the structure mobilizing reaction stresses at the soil-structure interface. Brandenberg et al. (2015) cited both the work of Sitar and Ostadan, the former stating that over prediction of seismic earth pressures with M-O 
theory was to be expected, and the latter concluding the opposite, with numerical results showing that M-O method significantly under predicts seismic earth pressure. Brandenberg et al. (2015) illustrates a simplified approach using the frequency domain solution for a given seismic motion to predict pressure versus depth, as well as a simplified process using a single frequency. The results of Brandenberg et al. (2015) are shown in figure 6, where they are compared with both the work of Ostadan (2005) and Sitar (2010).
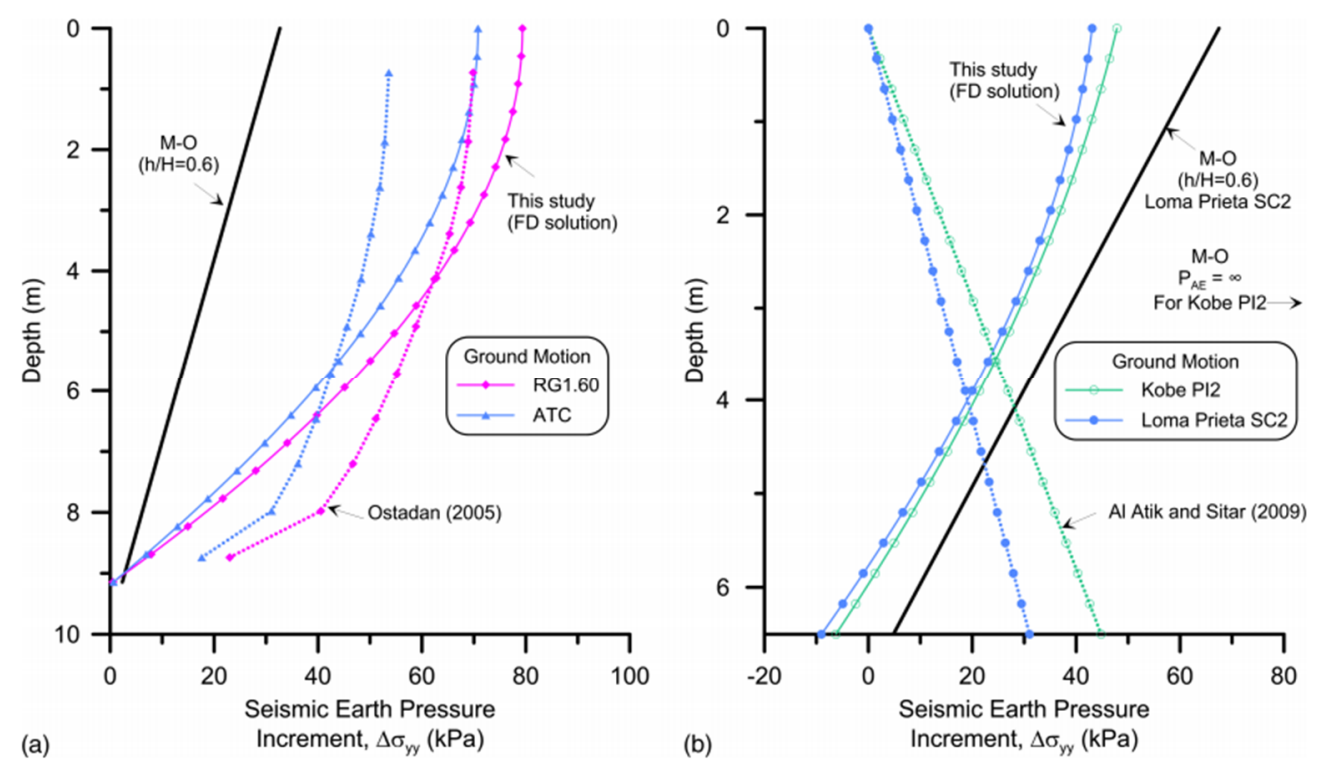

Figure 6: Results of Seismic Earth Pressure Vs. Depth Computed using Simplified Approach in Comparison with Ostadan (2005) and Sitar (2010), (Brandenberg et al. 2015) Ultimately, Brandenberg et al. (2015) makes the case for both observations regarding M-O method. 


\subsection{Summary of Review}

M-O method has been regarded as at the forefront of calculating seismic earth pressures on embedded structures. Originally developed for retaining walls in cohesionless soil, it has been modified by Seed \& Whitman (1970) and applied to many different soil conditions. Ostadan (2005) argues that M-O method severely underestimates the pressures on a rigid basement wall because of the lack of active earth conditions. Sitar et al. (2010 \& 2013) concludes that M-O method overestimates seismic earth pressures on retaining walls because the dynamic wall moment is not always exactly the sum of dynamic wall pressures and inertial wall forces.

There are multiple case study histories where non-seismically designed displacing retaining walls have been adequate for ground shaking (Gazetas et al. 2004) although these cannot directly be related to rigid embedded walls. Brandenberg et al. (2015) shows that both the work of Ostadan (2005) and Sitar et al. (2010) can be shown as valid and presents a unifying approach for doing so. Currently, the state of practice presented in NEHRP (2012) concludes that SSI effects are generally neglected in practice, with retaining walls being no exception.

In conclusion, there have been numerous approaches to model seismic retaining wall pressures for displacing and non-displacing conditions. Our work aims to take 'snapshots' of the SSI spectrum, and showcase under what conditions seismic pressures follow the distributions described by both Ostadan (2005) \& Al Atik \& Sitar et al. (2010). Evaluating the validity of the modified M-O method is also another inherent objective of this study. 


\section{CHAPTER 3 EXPERIMENTAL SET UP}

\subsection{Defining the Problem}

The diverging conclusions of Ostadan (2005) and Al Atik \& Sitar (2010) were well defined by Brandenberg et al. (2015), but neither was disproven. The case remained to explain the results of the former and the latter. Brandenberg et al. states that the approach taken to support both the arguments of Ostadan (2005) and Al Atik \& Sitar (2010) is simplified in several ways, most importantly that the effects of wall and foundation inertia are not considered in the approach (i.e. kinematic SSI). Brandenberg comments that inertial effects have different demands on a structure than kinematic ones, and as such may or may not be in phase with them during a seismic event.

Our approach examines the situation of multiple retaining walls in uniform, cohesionless soil, above the water table. The different wall types and the soil they retain can explain the varying seismic earth pressure proposed by Ostadan (2005) and Al Atik \& Sitar (2010). Tabular functions can be used to describe the relative accelerations of both the ground surface and the bedrock with respect to time. Each seismic event has a unique tabular function with respect to time. From these functions, we can use transfer functions to achieve a model of acceleration with respect to frequency (i.e. a Fourier transform from the time to frequency domain).

It is hypothesized the maximum out of phase accelerations of the retaining wall (or any given structure for that matter) and the surrounding soil medium will only occur at certain frequencies. These will depend on the physical characteristics of the wall, the soil, and would explain the higher than M-O seismic pressures predicted by Ostadan (2005). Conversely, when the retaining wall or similar structure accelerates in phase with the surrounding soil medium, we hypothesize that a smaller than M-O seismic pressure resultant will be developed, similar to the results of Al Atik \& Sitar (2010). 


\subsection{Basis of Finite Element Method Used in Model Set-Up}

The finite element solution method is largely unchanged since its first implementation during the 1960's. (de Weck \& Kim, 2004) It discretizes a given physical model, in this case a retaining wall embedded in a soil medium, into individual parts or elements. The elements make up a finite size mesh and are connected to each other using nodes, which can be represented using systems of equations that are then solved simultaneously. The rate of achieving a given solution depends upon computing power available, the complexity of the problem, and how the problem is formulated and discretized. Elasticity and plasticity are modeled through the fundamental concept of stiffness and displacement. Finite element solutions are considered approximations due to the fact that they utilize limited degrees of freedom in order to function. The accuracy of the approximation to reality depends on detailed input of individual material properties and their interactions. The finite element method can be used to create relatively accurate approximations to many different boundary problems, the retaining wall problem being no exception.

\subsection{Summary of Model Software and Parameters}

We used ABAQUS v6.14 finite element software in our analysis. ABAQUS CAE/standard was used, as opposed to an explicit analysis. An implicit solver uses the same method as an explicit one to achieve results, with some added differences. 
- An explicit method updates the stiffness matrix after each time increment and reinserts the updated matrix back into the original problem. The next increment and its associated loads, boundary conditions, etc. is applied, and the process is repeated again.

- Explicit analysis time increments must be small enough for the final approximation to be accurate and not 'drift' away from the actual solution.

- An explicit solver is useful for high speed 'crash dynamic' type problems, which undergo large deformations over a relatively short period of time. Additionally, the computational cost of an explicit analysis is much smaller than an implicit one.

In addition to these characteristics, an implicit analysis also incorporates the following into achieving an approximation:

-An implicit analysis uses Newton-Raphson iterations after each increment to maintain equilibrium of the internal structure and externally applied forces.

-Implicit analyses reduce 'drift' of the approximation, but can be computationally costly as N-R iterations must be performed after every incremental step.

The standard/implicit solver was used to better capture the non-reflecting boundary characteristics, which are mentioned in depth in 2.6.4. Both methods are described in further depth in the ABAQUS Documentation (Dassault Systèmes Simulia, 2014)

The setup was analyzed in 2-D, plane strain conditions, assuming that wall end effects are negligible. Two dimensional results can be more easily compared to existing work. This eases calibration of the model and reduces computational power required to achieve an adequate solution. The model consists of two distinct separate parts, the wall and soil. The soil is homogenous, cohesionless sand. The wall is represented by a homogeneous plane strain material. Wall reinforcement is not taken into account in the model as it does not pertain to our study. A 
summary of both the general soil and wall properties is listed as follows in Table 1. For the purpose of continuity, all of the units in this study are in SI metric.

3.4 Constitutive Models for Soil Behavior

The soil constitutive model for the cohesionless sand uses the linear extended Drucker-Prager constitutive model with hardening. Although the Mohr-Coulomb constitutive model is commonly utilized, the Drucker-Prager model was chosen for the study as it allows a solution to be approximated by ABAQUS without the problem of convergence that arises for cohesionless soils without a surcharge pressure. (Popescu, 2016) Use of the Mohr-Columb model was initially attempted, but abandoned, as convergence of the solution would only occur using cohesion values upwards of $15 \mathrm{kPa}$ (i.e. not representative of a cohesionless soil). Additionally, the Drucker-Prager model is relevant because it can consider stress history effects, stress paths, dilatancy, and intermediate principal stresses (Helwany, 2007).

\subsection{Summary of General Drucker-Prager \& extended Drucker-Prager Models}

The general Drucker-Prager Method is a type of yield criterion, which is dependent on pressure to determine the plastic response of a given material. It can also be applied to materials including concrete, foams, plastics, which also utilize a pressure dependent response in finite element analyses to determine plastic yield strength. The general form equation of the yield criterion, expressed in terms of equivalent stress, $\sigma_{\mathrm{e}}$, or von Mises stress can be written as follows:

$\sigma_{e}=a+b \sigma_{m}$

Where $a$ and $b$ are material specific constants, and $\sigma_{\mathrm{m}}$ is the equivalent hydrostatic (mean) stress. (Drucker \& Prager, 1952) 
Converting the equation from equivalent stress terms to principal stress terms:

$\sqrt{\frac{1}{6}\left[\left(\sigma_{1}-\sigma_{2}\right)^{2}+\left(\sigma_{2}-\sigma_{3}\right)^{2}+\left(\sigma_{3}-\sigma_{1}\right)^{2}\right]}=X+Y\left(\sigma_{1}+\sigma_{2}+\sigma_{3}\right)$

Where $\sigma_{1,2,3}$ are principal stress values in the $\mathrm{x}, \mathrm{y}$ and $\mathrm{z}$ directions respectively, and $\mathrm{X}$ and $\mathrm{Y}$ are constants which relate the yield stress in tension and compression of the material as follows (Drucker \& Prager, 1952):

$X=\frac{2}{\sqrt{3}}\left(\frac{\sigma_{c} \sigma_{t}}{\sigma_{c}+\sigma_{t}}\right)$

$Y=\frac{1}{\sqrt{3}}\left(\frac{\sigma_{t}-\sigma_{c}}{\sigma_{c}+\sigma_{t}}\right)$

Where $\sigma_{\mathrm{c}}$ and $\sigma_{\mathrm{t}}$ represent yield stresses in compression and tension, respectively. The DruckerPrager Yield Surface is a smoothed version of the Mohr-Coulomb Yield Surface. For comparison, both yield surfaces in the П-Plane (principal stress plane) are shown in figure 7.

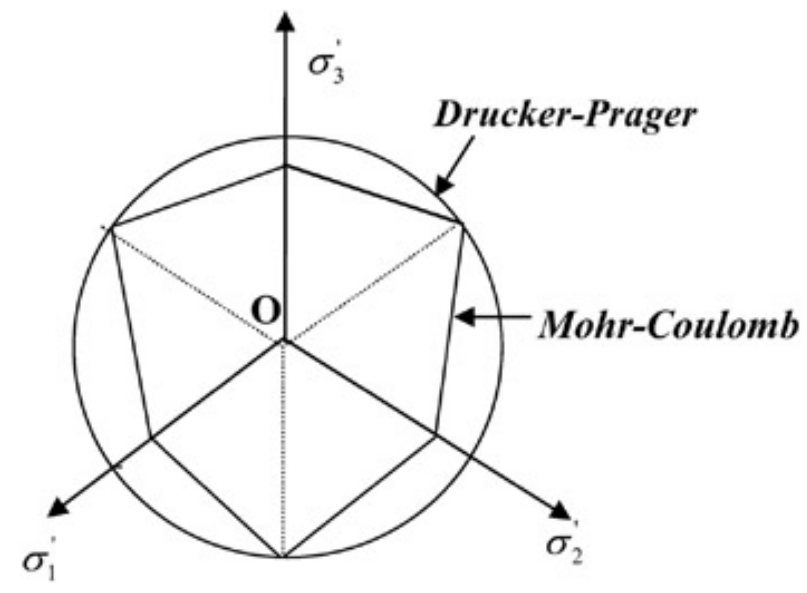

Figure 7: Comparison of Drucker-Prager and Mohr-Coulomb Yield Surfaces (from globalspec.com)

For constitutive soil modeling it is common to express soil behavior in terms of internal friction angle, $\varphi$, and cohesion, $c$; the constants A and B can be re-written in terms of these values, where the tensile yield stress is equivalent to zero. (Drucker \& Prager, 1952) The constants A and B can be thought of as modified friction and dilation angles in the Drucker-Prager Yield criterion. 
Equations (11) and (12) show how $\varphi$ (friction angle) and $c$ (cohesion) values in Mohr-Coulomb are converted to their Drucker-Prager values, $\beta$ and $d$, respectively.

$\tan \beta=\frac{6 \sin \varphi}{3-\sin \varphi}$

$d=\frac{18(c) \cos \varphi}{3-\sin \varphi}$

These parameters form the shear failure surface of the Drucker-Prager model as shown in equation (13). Note that for a cohesionless soil, $d=0$.

$F_{s}=t-p \tan \beta-d=0$

Where $\mathrm{F}_{\mathrm{s}}$ denotes the failure surface in the $\mathrm{p}$-t plane.

In future references, unless otherwise stated, all internal friction and dilation angle values will be assumed to be of the Drucker-Prager model for continuity.

The extended Drucker-Prager Model utilizes the general Drucker-Prager Yield Criterion, as well as incorporating hardening into the model. These parts together make up the yield surface of the model, shown in figure 8 . The shear failure region of the yield surfaces follows the equation of the Drucker-Prager Model listed above.

The hardening component of the model determines how the material strains with increasing equivalent hydrostatic (mean) stress applied. For materials that exhibit limited or no tensile capacity, such as granular soils or concrete, hardening is defined in compression. ABAQUS documentation specifically defines the tabular data for the hardening as uniaxial compressive stress versus volumetric plastic strain. (ABAQUS, 2014). Using references obtained from Helwany (2007), in addition to the work Tekeste, Raper, Tollner, \& Way (2007), the hardening data was calculated as follows. 


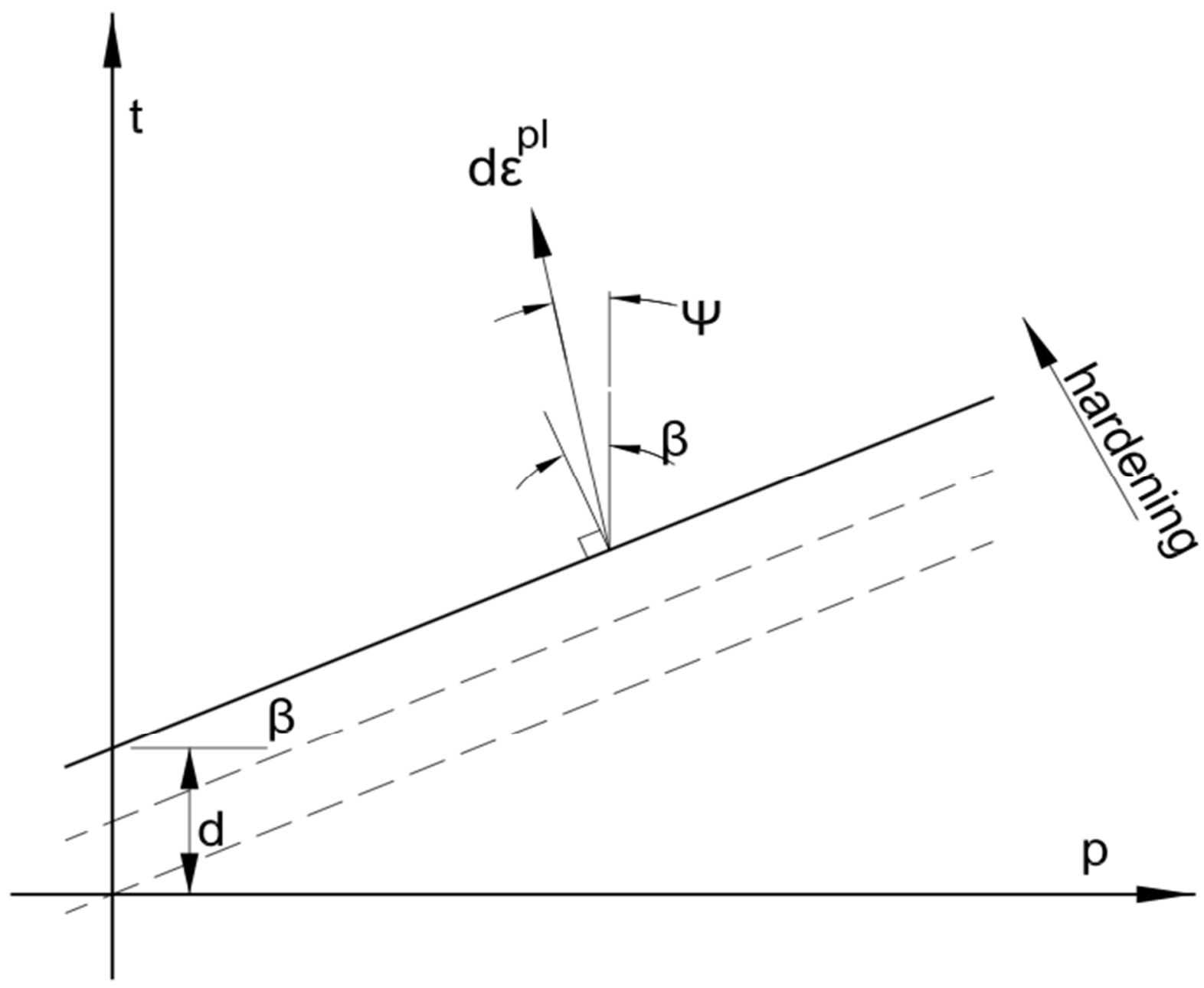

Figure 8: Linear Drucker-Prager Yield Surface with Hardening in the p-t Plane (Adapted from ABAQUS User's Guide, 2014)

The volumetric plastic strain, $\varepsilon_{v}{ }^{p}$, can be determined in relation to the mean effective stress, $p^{\prime}$ as shown in Equation 14. (Helwany, 2007)

$\varepsilon_{v}^{p}=\frac{\lambda-\kappa}{1+e_{0}} \ln \frac{p^{\prime}}{p_{0}}=\frac{C_{c}-C_{S}}{2.3\left(1+e_{0}\right)} \ln \frac{p^{\prime}}{p^{\prime}}$.

Where $\lambda$ and $\kappa$ are coefficients related to the slopes of isotropic consolidation and swelling cycles of the soil, $p_{o}{ }^{\prime}$ is the initial mean effective stress, $\mathrm{e}_{\mathrm{o}}$ is the initial void ratio, and $\mathrm{C}_{\mathrm{c}}$ and $\mathrm{C}_{\mathrm{s}}$ are coefficients of consolidation and swelling, respectively. The mean effective sress, $p$, which is 
identical to $\sigma_{m}$ in Eq. (7) is calculated as shown in Equation 15. (Helwany, 2007) \& (Tekeste, 2007)

$p^{\prime}=\left(\sigma_{1}^{\prime}+2 \sigma_{3}^{\prime}\right) / 3$

Where $\sigma_{3}^{\prime}=\sigma_{2}$. The hardening curve is shown in figure 9 for clarity. Together, these properties make up the entire constitutive model used for the soil model in ABAQUS.

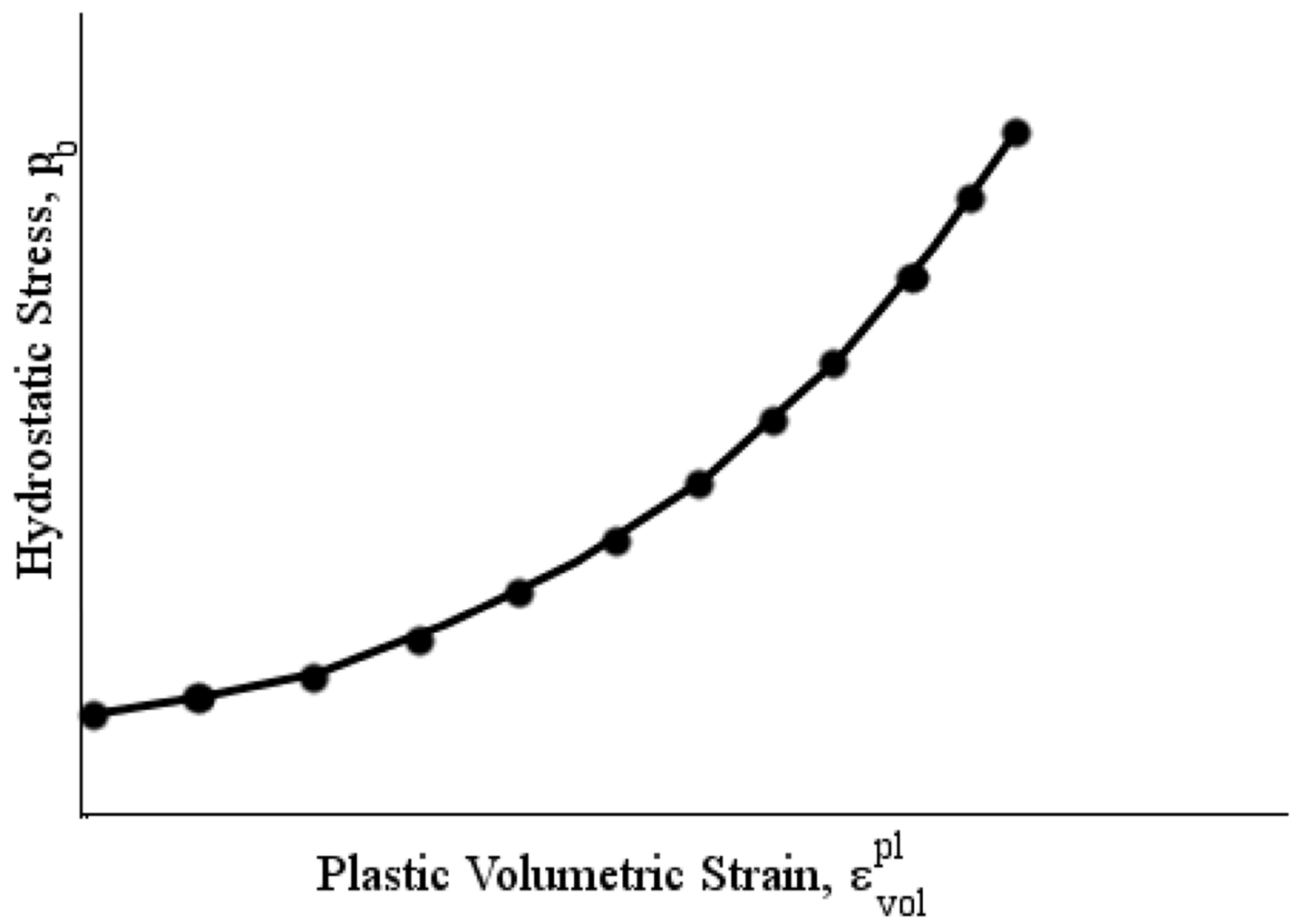

Figure 9: Hardening Behavior of Soil (Adapted from Helwany, 2007) Originally Adapted from ABAQUS (2002) 


\subsection{Model Parameters and Set-up}

As stated before, the models being input through ABAQUS are two-dimensional representations of retaining walls and basement walls of infinite length in a uniform, cohesionless soil medium.

The depth of the soil for the model was selected as 30 meters, and each wall has a height of 10 meters. This was done for dimensional consistency, and to easily calculate the resonant frequency of the soil column. $V_{\mathrm{s} 30}$, or shear wave velocity of the top 30 meters of the soil is most commonly used to calculate the resonant frequency. The overall length of the elastic half-space for each problem is 200 meters. This length was chosen after trial and error, as an appropriate distance to achieve adequate response of the non-reflecting boundary. A detail of each wall setup is shown in figures 10-12 for clarity. 


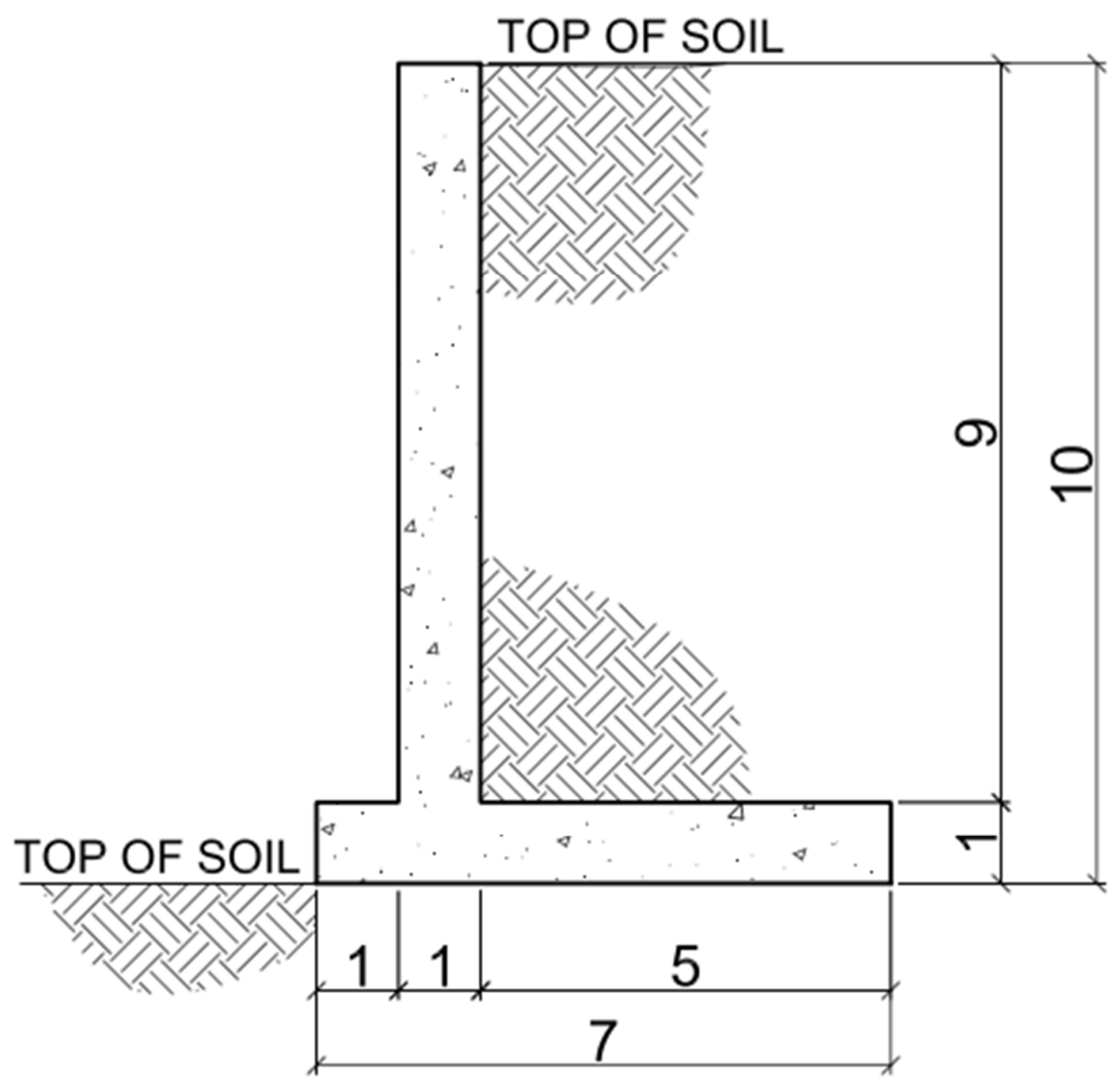

Figure 10: Wall dimensions for Cantilever Wall Model 


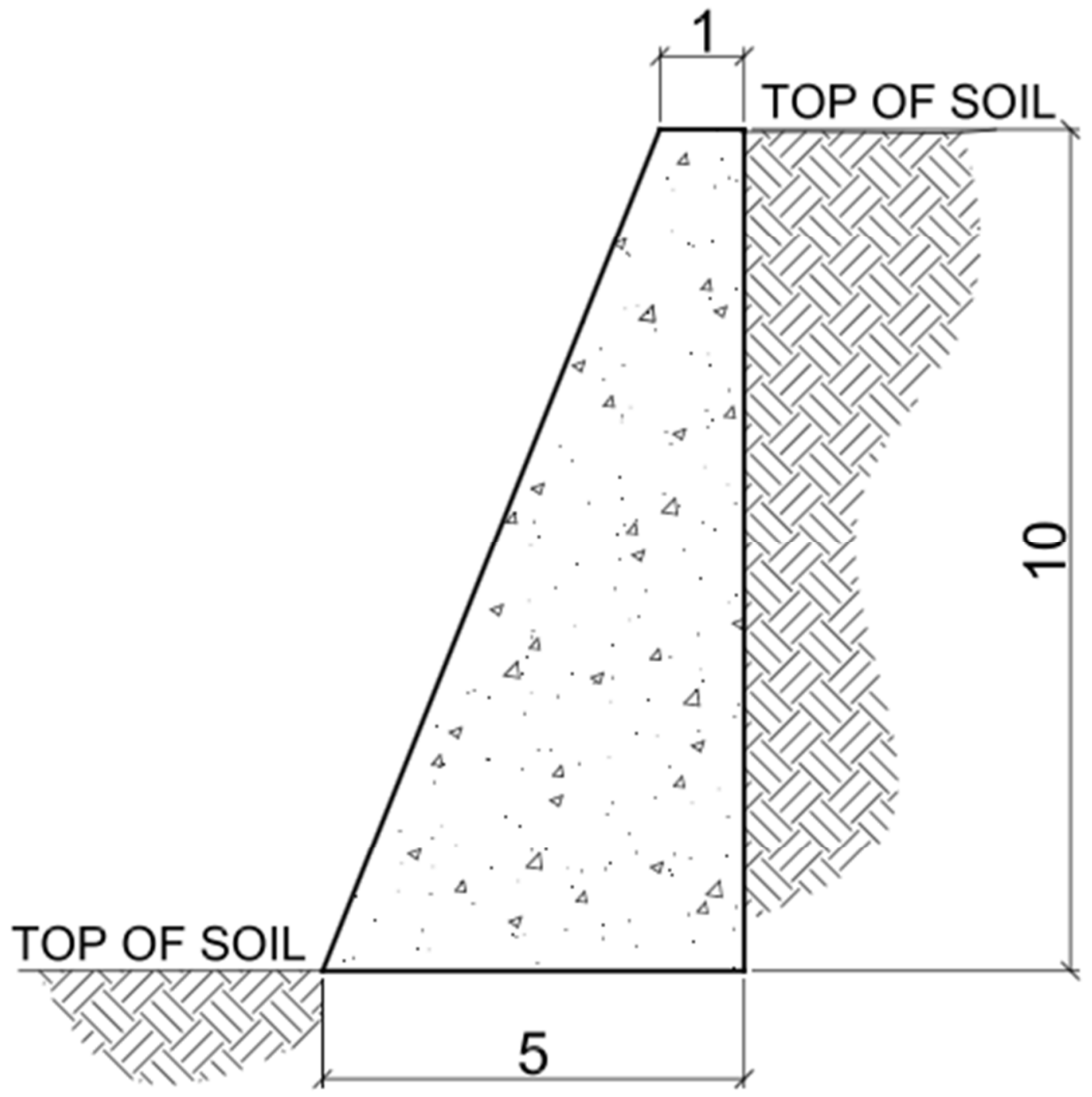

Figure 11: Wall dimensions for Gravity Wall Model 


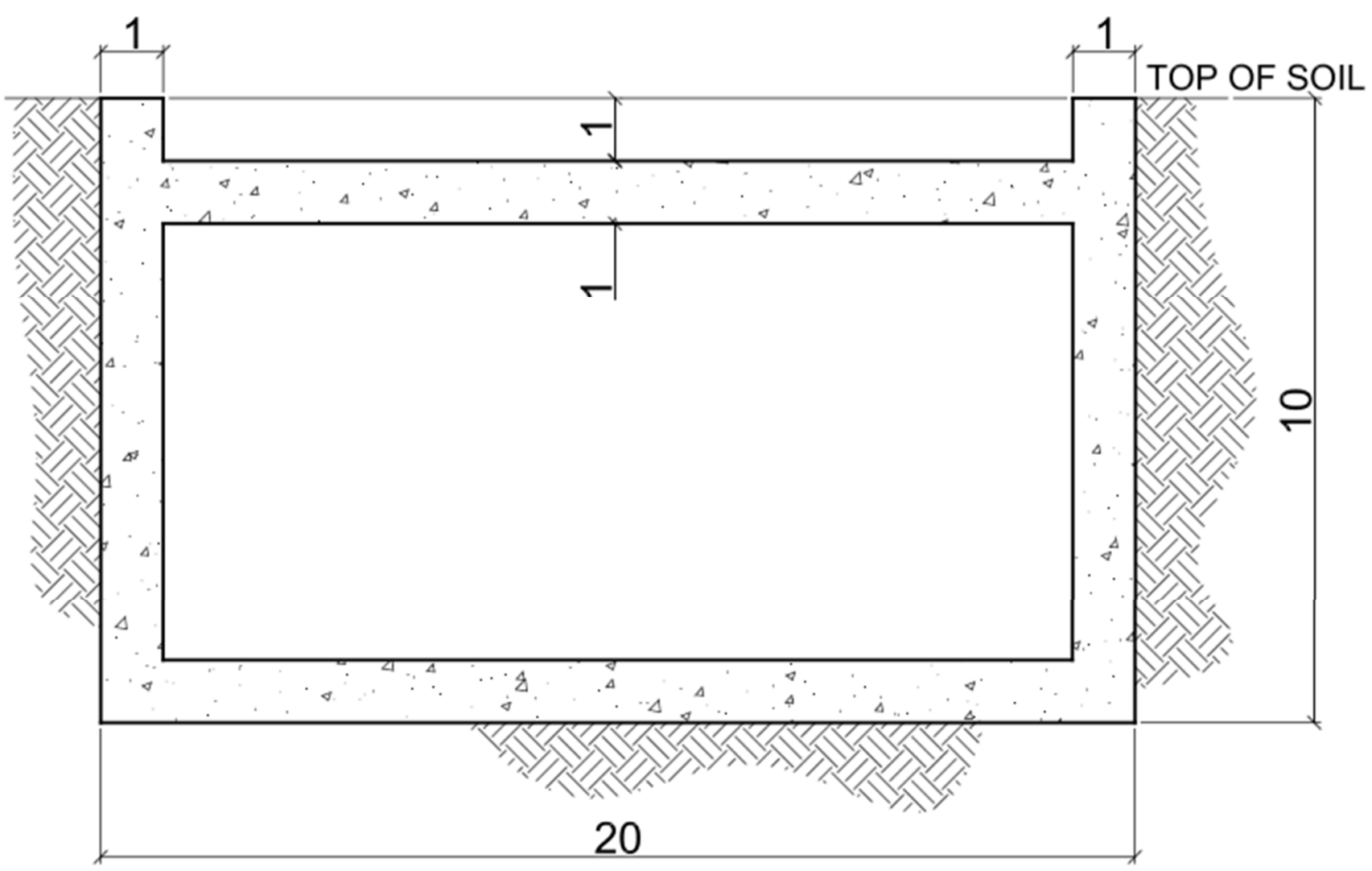

Figure 12: Wall dimensions for Basement Wall Model

The material properties of both the wall and the soil are listed in Table 1. The properties listed include those used for elastic, plastic, and general mechanical properties. The associated Drucker-Prager Hardening Curve is shown in figure 13. Specific properties dealing with contact friction between the wall and the soil are described in the following pages of this section.

Table 1: Wall Material Properties

\begin{tabular}{|r|c|c|}
\hline Mass Density & 2400 & $\mathrm{~kg} / \mathrm{m} 3$ \\
\hline Elastic Type & Isotropic & \\
\hline $\begin{array}{r}\text { Young's } \\
\text { Modulus }\end{array}$ & 41000 & $\mathrm{MPa}$ \\
\hline Poisson's Ratio & 0.2 & - \\
\hline
\end{tabular}


Table 2: Soil Material Properties

\begin{tabular}{|c|c|c|}
\hline Mass Density & 1900 & $\mathrm{~kg} / \mathrm{m} 3$ \\
\hline Elastic Type & Isotropic & \\
\hline $\begin{array}{l}\text { Young's } \\
\text { Modulus }\end{array}$ & $6.00 \mathrm{E}+07$ & $\mathrm{~Pa}$ \\
\hline Poisson's Ratio & 0.33 & - \\
\hline $\begin{array}{l}\text { Drucker Prager } \\
\text { Shear Criterion }\end{array}$ & Linear & - \\
\hline $\begin{array}{c}\text { Drucker-Prager } \\
\text { Friction Angle }\end{array}$ & 50.19 & Deg \\
\hline $\begin{array}{r}\text { FlowStress } \\
\text { Ratio } \\
\end{array}$ & 1.0 & - \\
\hline $\begin{array}{c}\text { Drucker-Prager } \\
\text { Dilation Angle }\end{array}$ & 0.0 & Deg \\
\hline $\begin{array}{r}\text { Drucker Prager } \\
\text { Hardening } \\
\end{array}$ & Yes & - \\
\hline Behavior Type: & Compression & - \\
\hline $\begin{array}{r}\text { Initial Void } \\
\text { Ratio, } \mathrm{e}_{0}\end{array}$ & 0.6 & - \\
\hline $\begin{array}{r}\text { Initial effective } \\
\text { Stress, } \mathrm{p}^{\prime}{ }_{0} \\
\end{array}$ & 200 & $\mathrm{kPa}$ \\
\hline $\begin{array}{r}\text { Compression } \\
\text { Index, } \mathrm{C}_{\mathrm{c}}\end{array}$ & 0.001 & - \\
\hline $\begin{array}{r}\text { Swelling Index, } \\
\mathrm{C}_{\mathrm{s}}\end{array}$ & 0.0001 & - \\
\hline
\end{tabular}




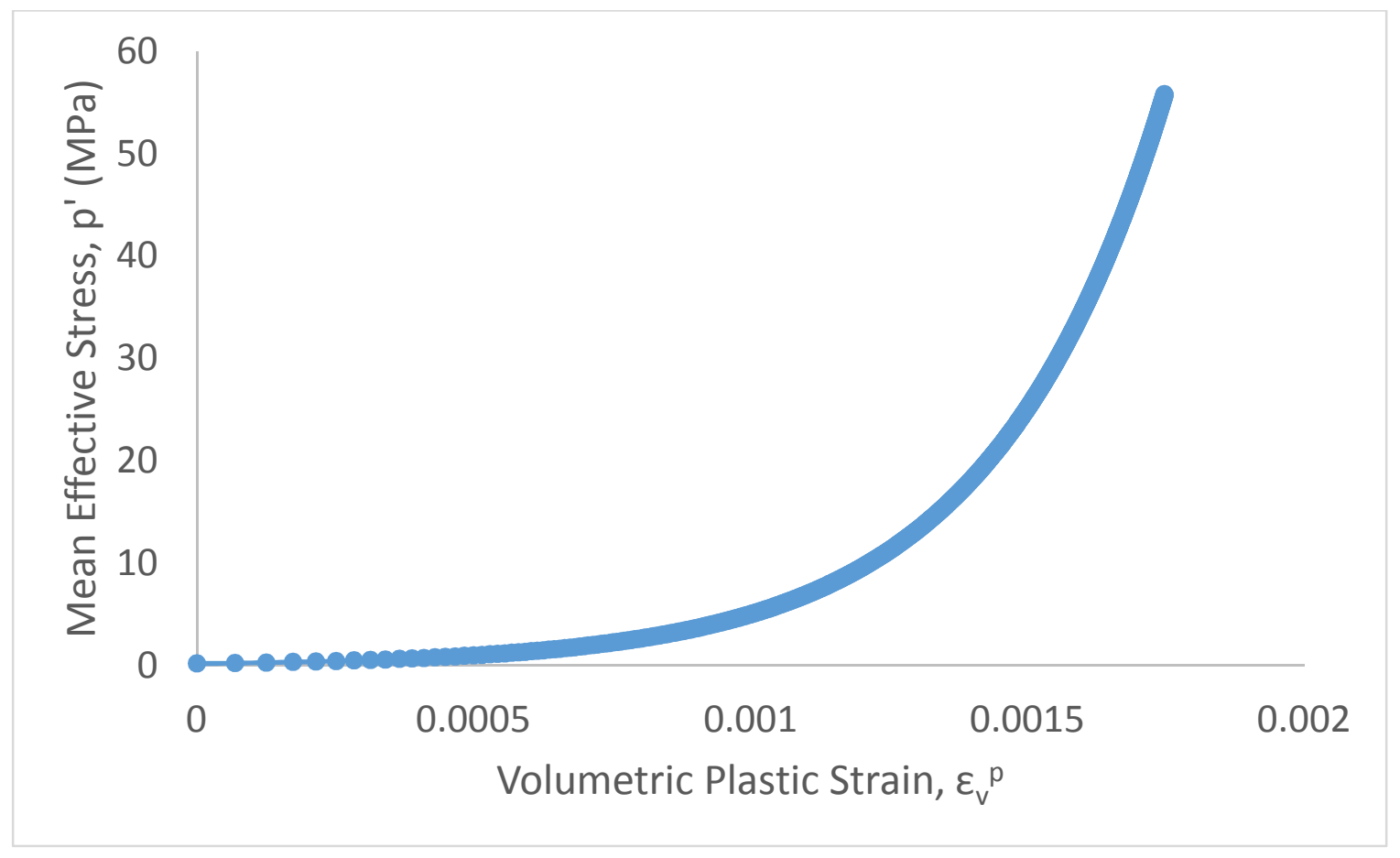

Figure 13: Drucker-Prager Hardening Curve For Constitutive Soil Model

\subsubsection{Boundary Conditions and Element Meshing}

One of the most important areas of calibration for any finite element model is the definition of the boundary conditions. In order to accurately describe an infinite elastic half-space for the purposes of this study, the boundary conditions have been well documented and evaluated against different methods described herein. Within the ABAQUS/CAE environment, there is variability in the selection of element types, mesh size, meshing algorithms, and other parameters such as contact properties, all of which can be made more or less specific to increase accuracy of the final approximation.

The soil part for the model was defined as a two-dimensional, shell, planar part, with material properties based off the corresponding section assignment for the soil. The section properties as listed in Table 2 were used to build a section using mass density, elasticity, plasticity, and hardening attributes. The soil part was then meshed using plane strain elements. 
Initially, linear, plane strain elements with reduced integration (ABAQUS Designation CPE4R) were chosen due to the efficiency in computation time, and ease of calibration. These elements were then changed to quadratic plane strain elements (ABAQUS Designation CPE8R), and the two results were then compared with one another. The final models utilized linear elements because there was little variation in the results between these and quadratic ones (less than 5\% difference for. A convergence study was performed on the mesh size nearest to the wall. Contact pressure results between the soil and the wall were found to be almost identical (less than $8 \%$ difference) between an element size of 0.5 meters or 0.25 meters, indicating convergence. 0.25 meter mesh size was utilized in the final models at the wall-soil boundary because the computational time was marginally longer than with a 0.5 meter mesh. A coarser mesh of approximately 0.5 by 2 meter size was used further away from the wall-soil boundary. Figures 14 through 16 show the meshing used for each separate model.

The edges of the soil were modeled using infinite plane strain elements (CINPE4) to provide the non-reflecting boundary crucial to ensuring accurate free-field response away from the soil-wall interface. These elements were modeled with a length of approximately 20 meters to better capture the displacement of the model due to the input base acceleration without any unintended deformations of the finite element mesh.

In order to capture the non-reflecting boundary condition, a sweep mesh algorithm was used, with the sweep direction corresponding to the direction of infinite ends of the model away from the wall-soil interface. ABAQUS/CAE does not support infinite elements explicitly within the GUI and subsequently manual changes were made though editing the input file in Windows Notepad. After the model was fully compiled together, a new job was created in ABAQUS. Then, through the ABAQUS Interface, the job was selected and an input file was written. This input file 
(.inp) was saved in the Temp folder by default and accessed in Notepad from there. In notepad, the elements along the boundary of the model were changed to infinite elements. Note that the elements to be changed were assigned as acoustic elements through the ABAQUS GUI initially, to be separately distinguished from other ones. The input file was saved, and then imported back into ABAQUS. The imported job could then be edited and changed as needed if necessary.

The retaining wall meshes used in the study, were coarse compared to the soil, with an element size of 0.5 meters square used for all cases. Because the stresses in the walls are not the focus of this study, the mesh size only needed to be dense enough to accurately model displacement of the wall. Meshing of the wall was controlled using the structured algorithm using quadratic, plane strain elements with reduced integration (CPE8R). The reason for utilizing quadratic elements over linear elements was to provide a relatively accurate deformation shape while maintaining a larger mesh size. The meshed system for all (3) different cases is shown for clarity in figures 14 through 16. 


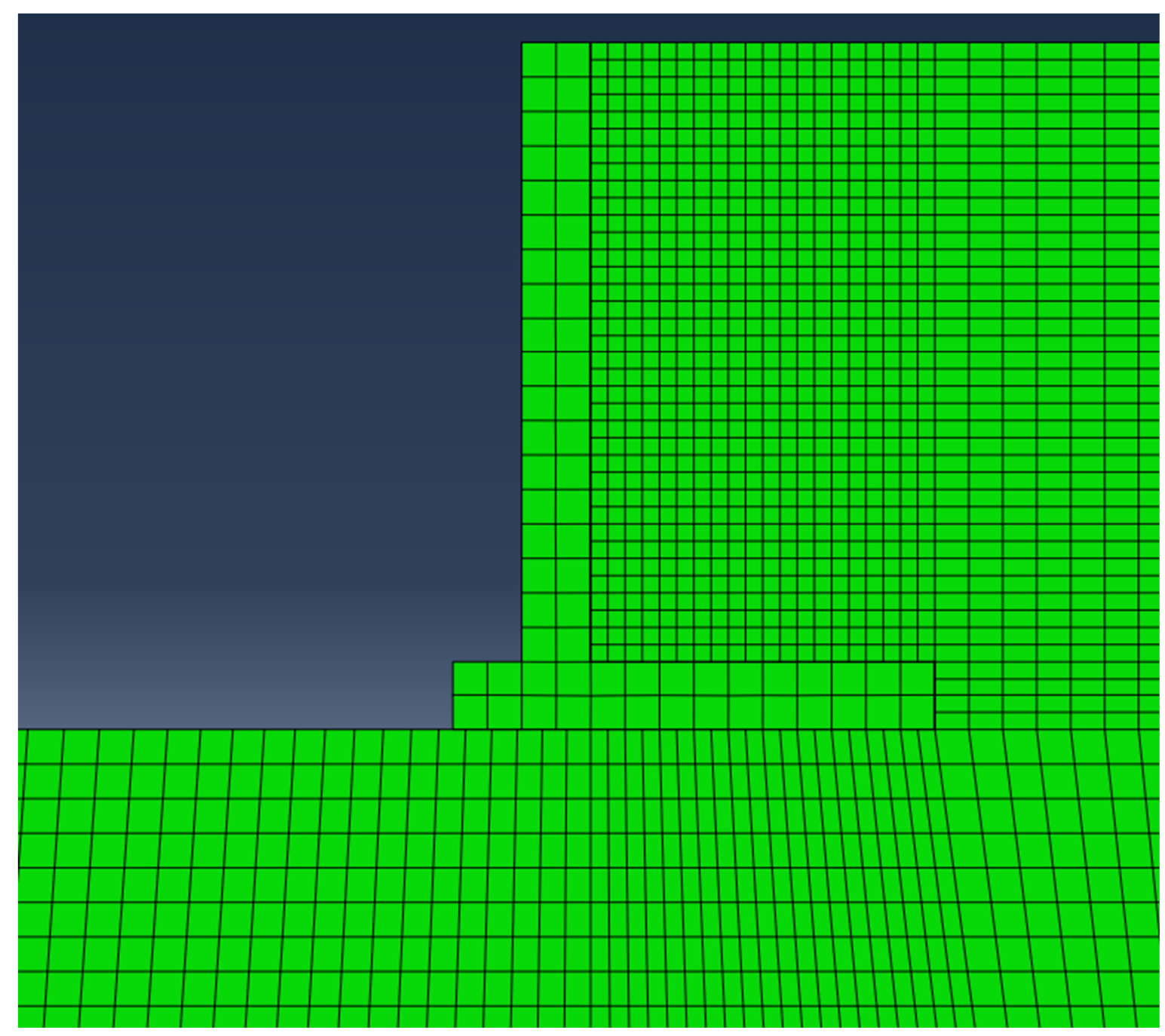

Figure 14: Initial Mesh of Cantilever Wall 


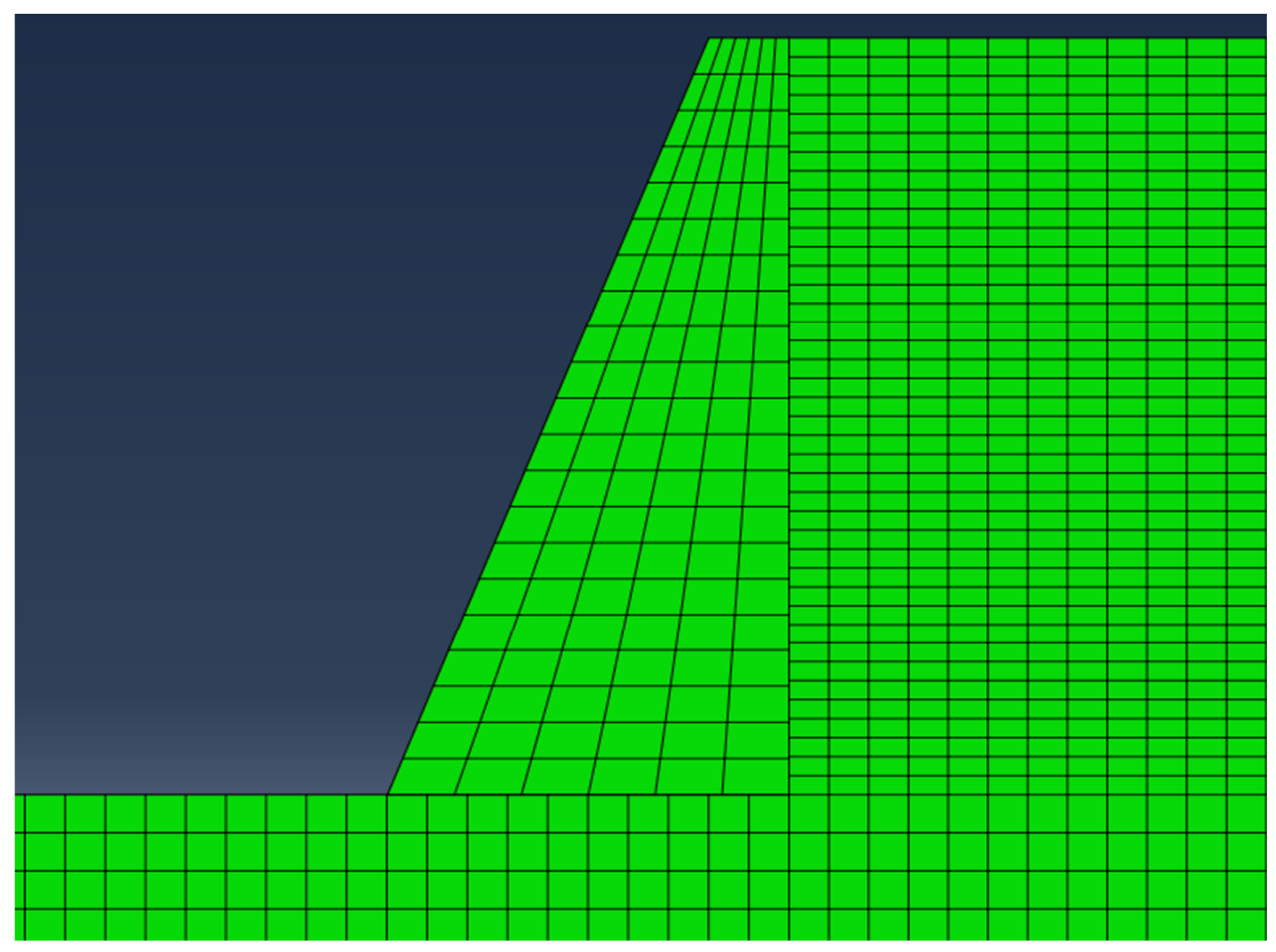

Figure 15: Initial Mesh of Gravity Wall

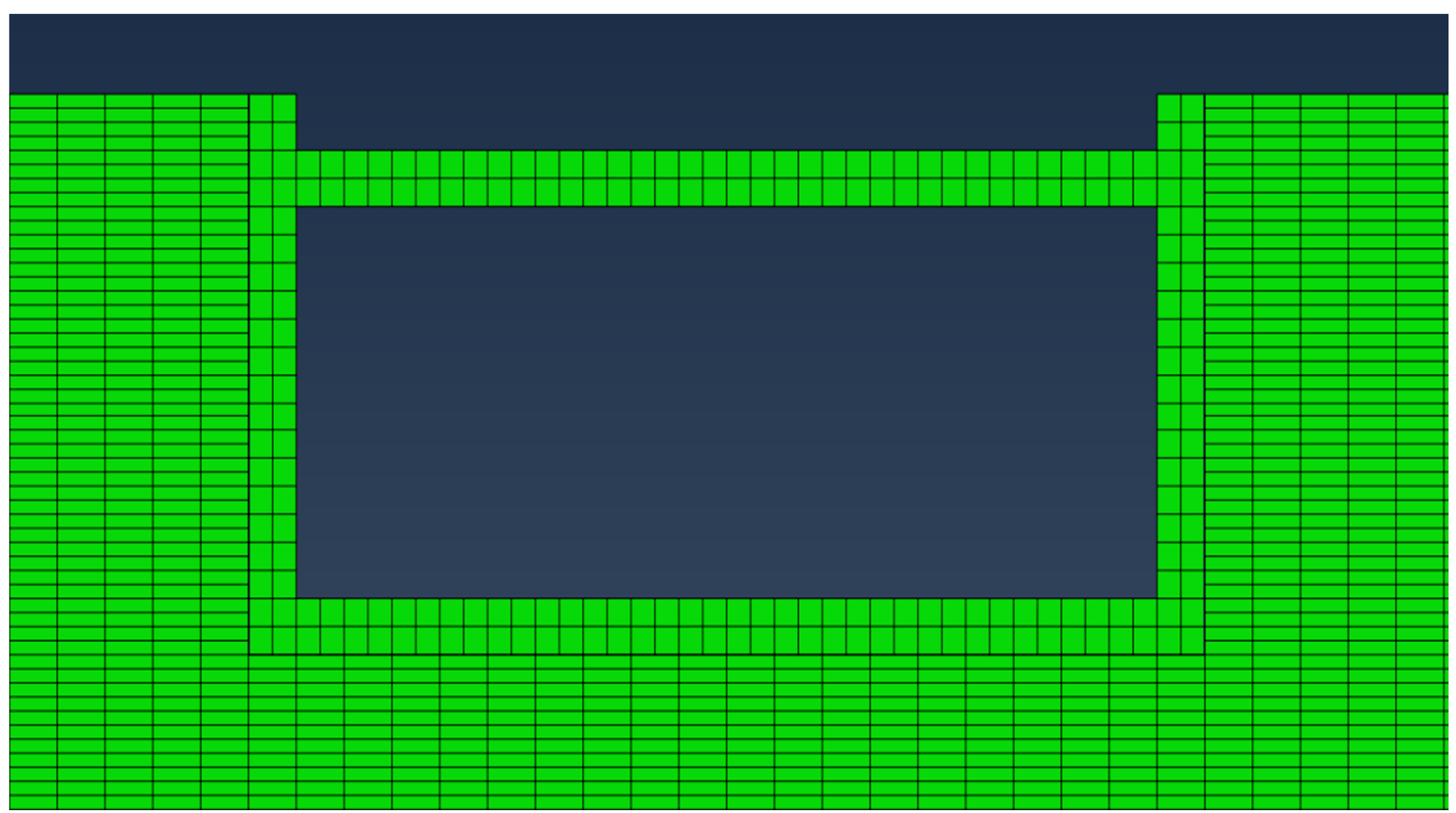

Figure 16: Initial Mesh of Basement Wall 


\subsubsection{Contact at Soil-Wall Interface}

Modeling the interaction between any two faces is a task unique to finite element analysis, because the properties are not inherently physically set up as they would be through an analytical analysis or through physical testing. Additionally, contact in ABAQUS is one of the most difficult parameters to emulate accurately. (Hall \& Kasper, 2016) A general rule of thumb of keeping the contact properties as simple as possible was employed for the analysis. Two different contact properties were used for each model. A 'surface to surface' contact condition was specified for both cases. The wall was chosen as the master surface in both cases, because it is the stiffer of the two materials contacting. (Popescu, 2016) A penalty tangential interaction and 'hard contact' normal condition was specified for both surfaces, with the coefficient of friction entered as 0.7 along the base and 0.3 along the sides. (finesoftware.eu). For reference, a rough contact simulation (infinite friction along the base of the wall) was run to compare the results, to which there was no noticeable difference in contact pressure.

\subsubsection{Damping of System}

Due to the soil's ability to reach resonance, the system required damping during the dynamic analysis. ABAQUS does not allow for structural damping (typically denoted as $c$ ) to occur during a dynamic procedure; Rayleigh damping was specified in lieu of this. ABAQUS allows the input of the coefficients $\alpha$ and $\beta$, calculated as follows ( $\mathrm{Ju} \& \mathrm{Ni}, 2007)$ :

$$
\begin{aligned}
& \alpha=2 \omega_{1} \omega_{2}\left(D_{1} \omega_{2}-D_{2} \omega_{1}\right) /\left(\omega_{2}^{2}-\omega_{1}^{2}\right) . \\
& \beta=2\left(D_{2} \omega_{2}-D_{1} \omega_{1}\right) /\left[\pi\left(\omega_{2}^{2}-\omega_{1}^{2}\right)\right] \ldots .
\end{aligned}
$$

Where $\omega_{i}$ represents the resonant circular frequency for a given mode, $i$, and $D_{n}$ is the percentage of critical damping. For both values of D, 5\% was used. Values of $\omega$ were determined by calculating the resonant period of the soil column behind the walls, using a shear wave velocity of 
300 meters per second. This value was chosen in order to ensure the model was not under damped, and realistically accurate.

\subsection{Setup Step-by-step Analysis}

All (3) different models were run through the same general analysis. After the preprocessing work was complete, an analysis for input was then created and used to define various boundary conditions, base accelerations and vectors, and other characteristics as described here. The analysis was broken up into (4) different steps; an initial step, a gravity step, a general static step, and finally a dynamic implicit step.

\subsubsection{Initial Step}

In the initial step of the analysis, interaction properties between the wall and the soil were defined, as well as model boundary conditions. Restraints of degrees of freedom 1 and 2, corresponding to $\mathrm{x}$ and $\mathrm{y}$ directions respectively were assigned to all exterior nodes of the assembly along the sides and base. Fixing the base of the model is representative of the boundary between the soil and rock layer below, where wave reflection occurs due to the abrupt change in stiffness between the soil and rock layers. Fixing the sides of the model at the infinite elements allows the settlement of the soil due to gravity effects without creating additional, non-realistic forces in the finite element blocks. These effects include the model expanding horizontally i.e. like a viscous fluid, as well as being held up along the sides, resulting in unnecessary shear effects along the boundaries.

\subsubsection{Gravity Step of Analysis}

After all of the initial properties of the assembly were defined, a gravity load was applied to the model before the static analysis. This was done by creating a geostatic step to be applied to the entire model. The typical value of $-9.81 \mathrm{~m} / \mathrm{s}^{2}$ was used in the $y$-direction. All of the boundary 
conditions were propagated from the initial step through to the gravity step, in addition to the interaction properties. A geostatic step was chosen to establish initial soil pressures before the dynamic step. The amplitude of the gravity load was ramped linearly from a value of 0 to 1 over a time period of 100 seconds, in a similar manner to the procedure outlined by Helwany, (2007). This is a common procedure when applying gravity loads to a finite element model. This is due to the fact that if the load is applied too quickly, or all at once, there is a resulting shockwave that develops at the boundary of the model, resulting in false non-linear deformations of the soil. Additionally, a boundary condition in the x-direction was introduced to restrain all nodes of the wall during the gravity application. This was done to simulate construction of the wall without lateral pressure of the soil being applied, in accordance with the work of Upadhyay, Krishna, and Singh (2011).

\subsubsection{General Static Step}

A general static step was applied after the gravity step and before the dynamic step for a period of 100 seconds. The $\mathrm{x}$-direction restraint on the wall was released during this step, and all other prescribed conditions from the gravity step remained constant. This was done to establish at-rest conditions on the walls. A time period of 100 seconds was chosen, to allow any resulting shockwaves from the release of the wall restraint to completely damp out before starting the dynamic analysis. Numerous runs were performed before and after inclusion of this step in the analysis to verify its importance on reduction of 'noise' in the system before the dynamic step.

\subsubsection{Dynamic Step of Analysis}

The dynamic step was created after static noise in the system was fully damped out. A dynamic implicit procedure was used to propagate the base motion of the model with the appropriate amplitudes and frequencies. All boundary conditions were propagated through to this 
step from the previous steps. Then, the boundary condition restraint in the x-direction was removed for all nodes corresponding to the base of the soil layer and sides where they intersected the infinite elements. In its place, an acceleration boundary condition was applied. A colloquial name for this condition is known as the 'bathtub effect', where all the free field response nodes possess the same acceleration time history characteristics. This same setup was used in Upadhyay, Krishna, and Singh (2011) for a similar finite element analysis setup of a retaining wall subjected to various ground motions where it was shown to be a valid method of inputting a base ground motion. An amplitude of $0.49 \mathrm{~m} / \mathrm{s}^{2}(0.05 \mathrm{~g})$ was assigned to the acceleration boundary condition. This was done to ensure little to no deformation of the soil. Because the dynamic pressures on the walls will be dependent on resonance of the wall and soil column, they are dependent on driving frequency, not amplitude.

\subsubsection{Driving Frequencies used in Acceleration Boundary Condition}

The driving frequencies used for the acceleration boundary condition were determined on the basis of comparison of reality, and to provide adequate sensitivity across the entire SSI spectrum that wanted to be observed. According to the USGS website, earthquake frequencies rarely occur above $20 \mathrm{~Hz}$ (USGS). This resulted as a $20 \mathrm{~Hz}$ driving frequency being the upper bound of acceleration frequency within the SSI spectrum. A lower bound of $0.1 \mathrm{~Hz}$ was chosen for multiple reasons. First, this was the lowest frequency that would reach its upper amplitude over a simulated time of (10) seconds for the dynamic analysis. Additionally, frequencies below 0.1 Hz resulted in negligible SSI effects compared to the results of higher driving frequencies, i.e. $1 \mathrm{~Hz}$, etc. assumedly resulting in a moot point to test frequencies any lower. 


\section{CHAPTER 4 RESULTS OF ANALYSES}

\subsection{Running of Analysis and Exporting Results}

After all of the models were successfully defined as described in the previous chapter, analyses were run through ABAQUS. A list of the following driving frequencies were used for each model; $0.1 \mathrm{~Hz}, 0.5 \mathrm{~Hz}, 1 \mathrm{~Hz}, 5 \mathrm{~Hz}, 10 \mathrm{~Hz}, \& 20 \mathrm{~Hz}$. After all of the analyses were run over a period of multiple days, the output database files for each model run were accessed through the ABAQUS GUI and the pertinent data for the study was manually extracted.

The following process was employed for each frequency run of each model, allowing consistent data to be acquired across a total of (18) separate analyses. First the output database for a given model was loaded and the animation of the dynamic analysis was visually observed, to ensure no unrealistic response from the model mesh had occurred. Following this, a node path was defined for each model, along the corresponding wall face, beginning with the second node from the top of the wall face, and extending down to the second to last node from the bottom of the wall face or node nearest to the final depth to be measured. These data points corresponded to 0.5 meter increments from an initial depth of 0.5 meters, to a final depth of 8.5 meters. Depths past 8.5 meters to the lowest depth of the wall (10 meters) had their pressure values neglected. This was because they often produced unrealistic results that did not correlate with the rest of the nodes along the wall face. This problem can possibly be attributed to hard corners of the mesh being subject to contact forces from more than one direction.

Once the path for the model was created, the contact pressure for each node along the path was plotted with respect to time, over the static (gravity) steps of the analysis and the dynamic step. Using the model setups described in the previous chapter, this allowed observation of at-rest conditions, followed by static, active conditions where they occurred, and finally dynamic active, 
as well as dynamic passive pressures, depending on the type of wall. The dynamic pressures with respect to time were then visually observed in ABAQUS before the data was extracted. This was done for multiple reasons. First, visually looking at the plot of pressures for every node with respect to time for the entire analysis allowed instances of 'static' or 'noise' in the model to be neglected in the dynamic results. This noise resulted in unrealistically high pressures against each of the (3) walls for approximately the first 0.1 seconds of each dynamic analysis. Second, maximum pressure values for each node along the path of each wall could be accurately observed and noted in the time domain, which did not necessarily occur at the same time(s). This was essential in order to properly envelope all of the pressure values for each wall at each frequency studied.

After the noise of the model was able to be sorted out and neglected for the dynamic analysis, temporary, 'XY data sets' were created again in the ABAQUS GUI, by creating XY Data from a path, and manually selecting the times noted where each node reached its maximum pressure during the extent of the dynamic portion of the analysis. Anywhere from a minimum of (5) to more than (20) sets of XY data were created for each analysis. Within each set of XY data, the contact pressure for each node along the wall path, and its distance from the start of the path was extracted. After these temporary data sets had been saved, XY data was created by 'operating on XY data' in the ABAQUS GUI. Then, all the data sets for each frequency of each analysis that had been previously saved were enveloped using the maxEnvelope() command. This command in ABAQUS takes each data set listed manually inside the parentheses, and outputs a maximum value for each ' $y$ ' value that corresponds with a single ' $x$ ' value. In this case, ' $y$ ' corresponds to the pressure, and ' $\mathrm{x}$ ' is the length along the path with respect to the starting point. Because ' $\mathrm{x}$ ' values for each node for each time selected remain constant, the dynamic, 'y' value of contact 
pressure could then be extracted. Following this, the reduced, enveloped set of data for each frequency, for each wall was then saved, also temporarily. Finally, each enveloped set of XY data was manually selected by right clicking, and selecting the 'Edit' command, to retrieve the values in spreadsheet format, after which they were finally copied and pasted in Microsoft Excel.

\subsection{Data from Analyses}

The data from each analysis, i.e. each driving frequency sampled, for each wall case is shown below. The multiple formats of the data were chosen for both analytical and visual relevance to the formal hypothesis of this study. Additionally, visualizations of each analysis are shown.

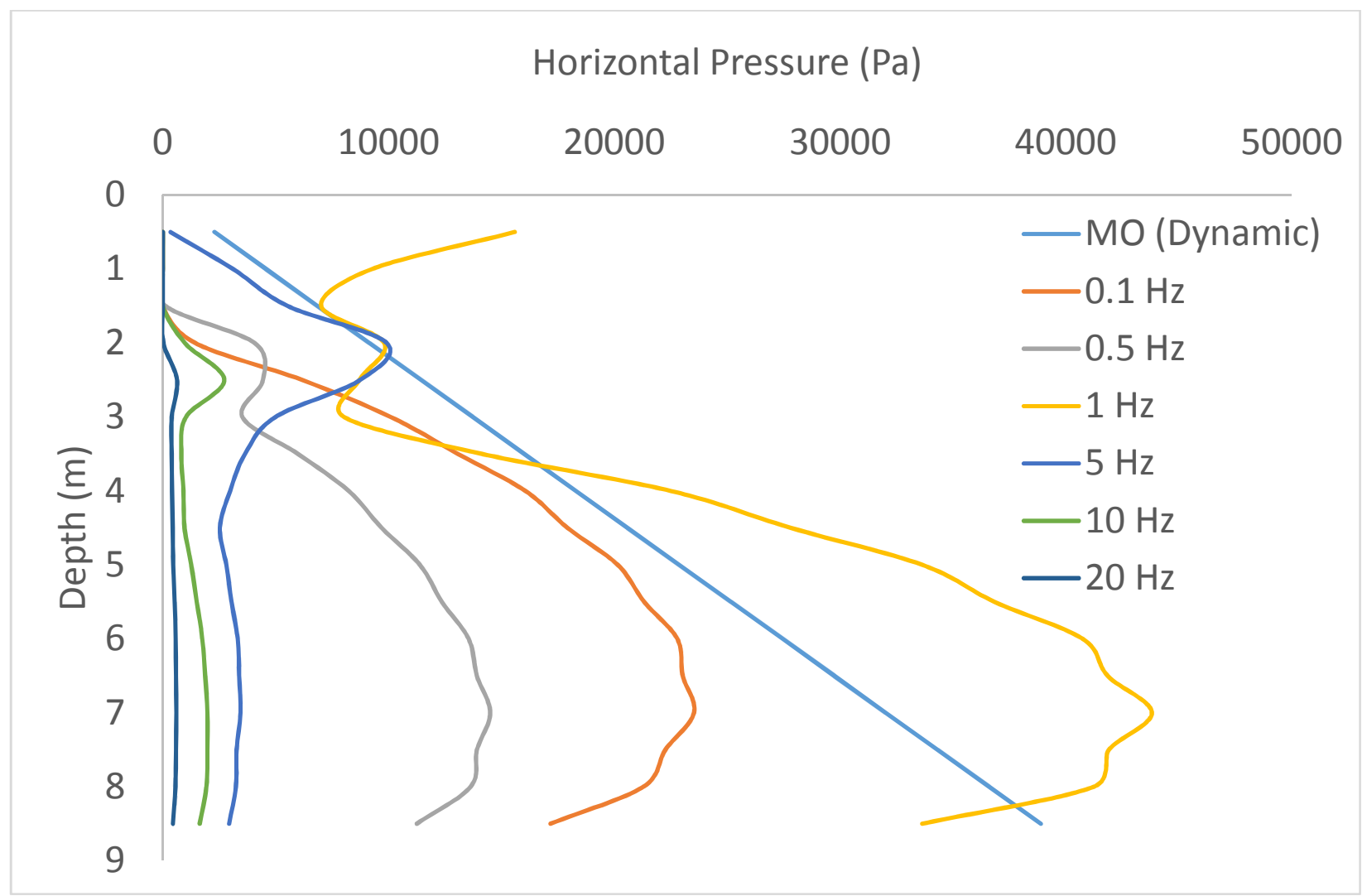

Figure 17: Dynamic Pressure Increment Vs. Depth For Cantilever Retaining Wall at Driving Frequencies Sampled 


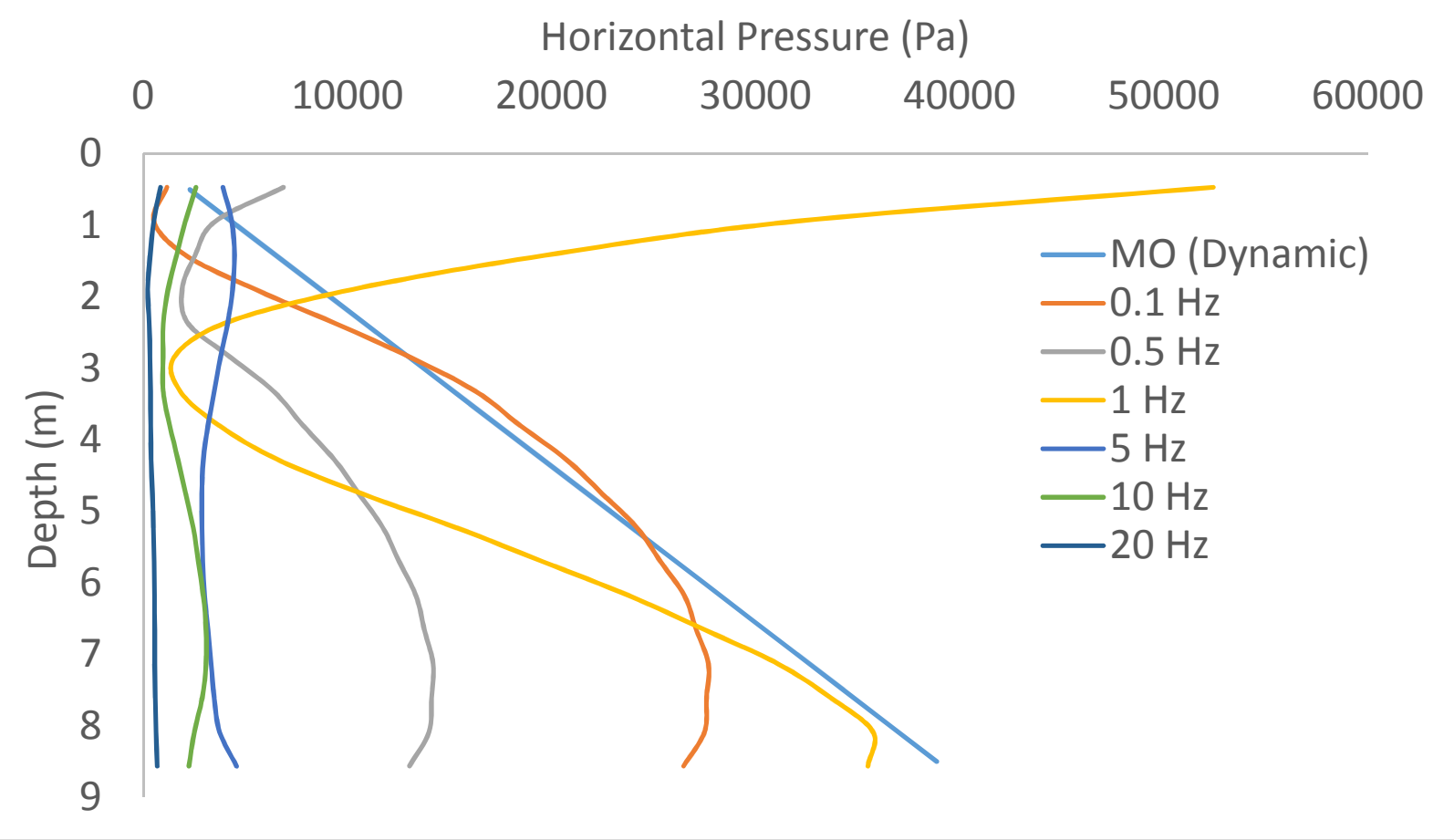

Figure 18: Dynamic Pressure Increment Vs. Depth For Gravity Retaining Wall at Driving Frequencies Sampled

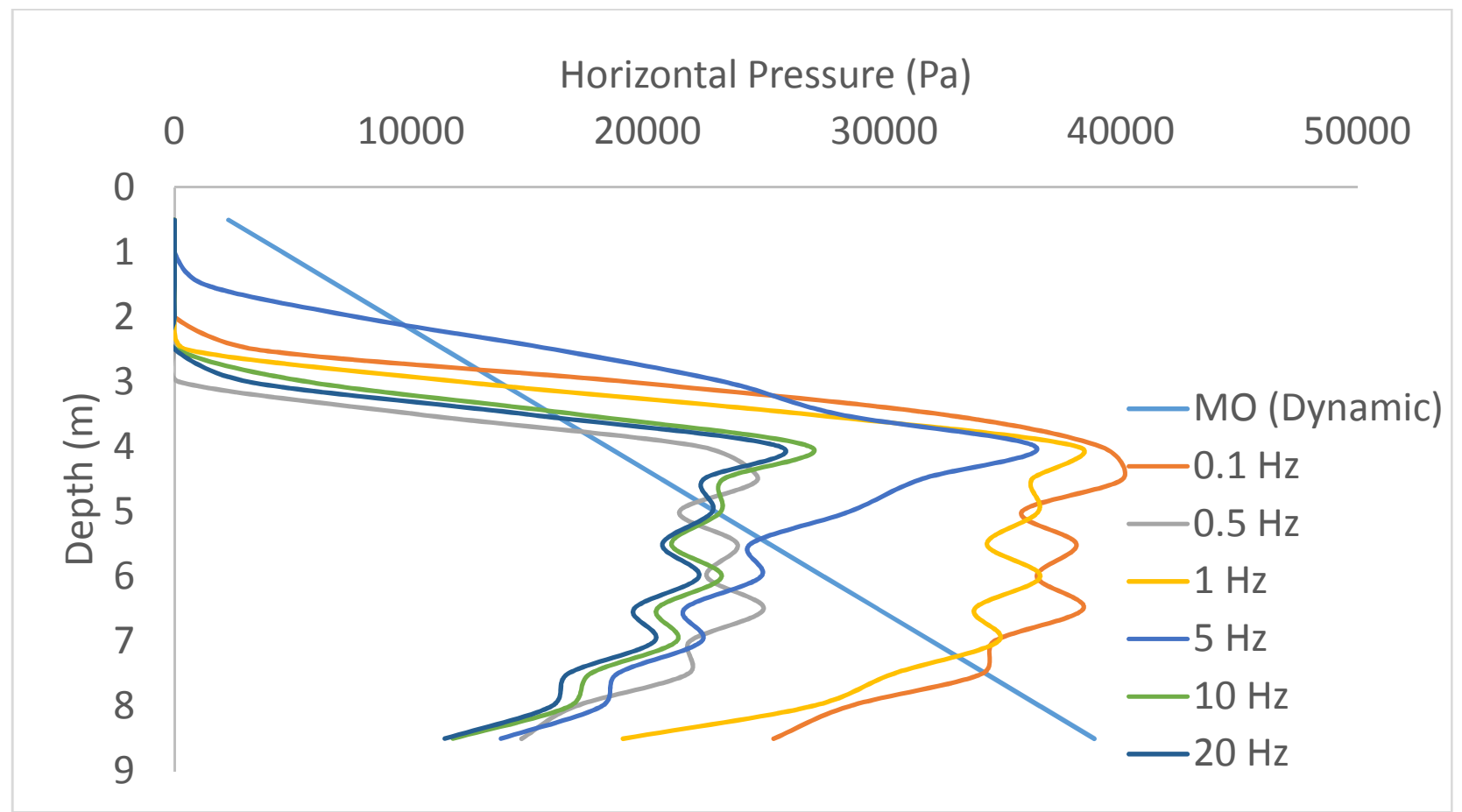

Figure 19: Dynamic Pressure Increment Vs. Depth For Basement Retaining Wall at Driving Frequencies Sampled 


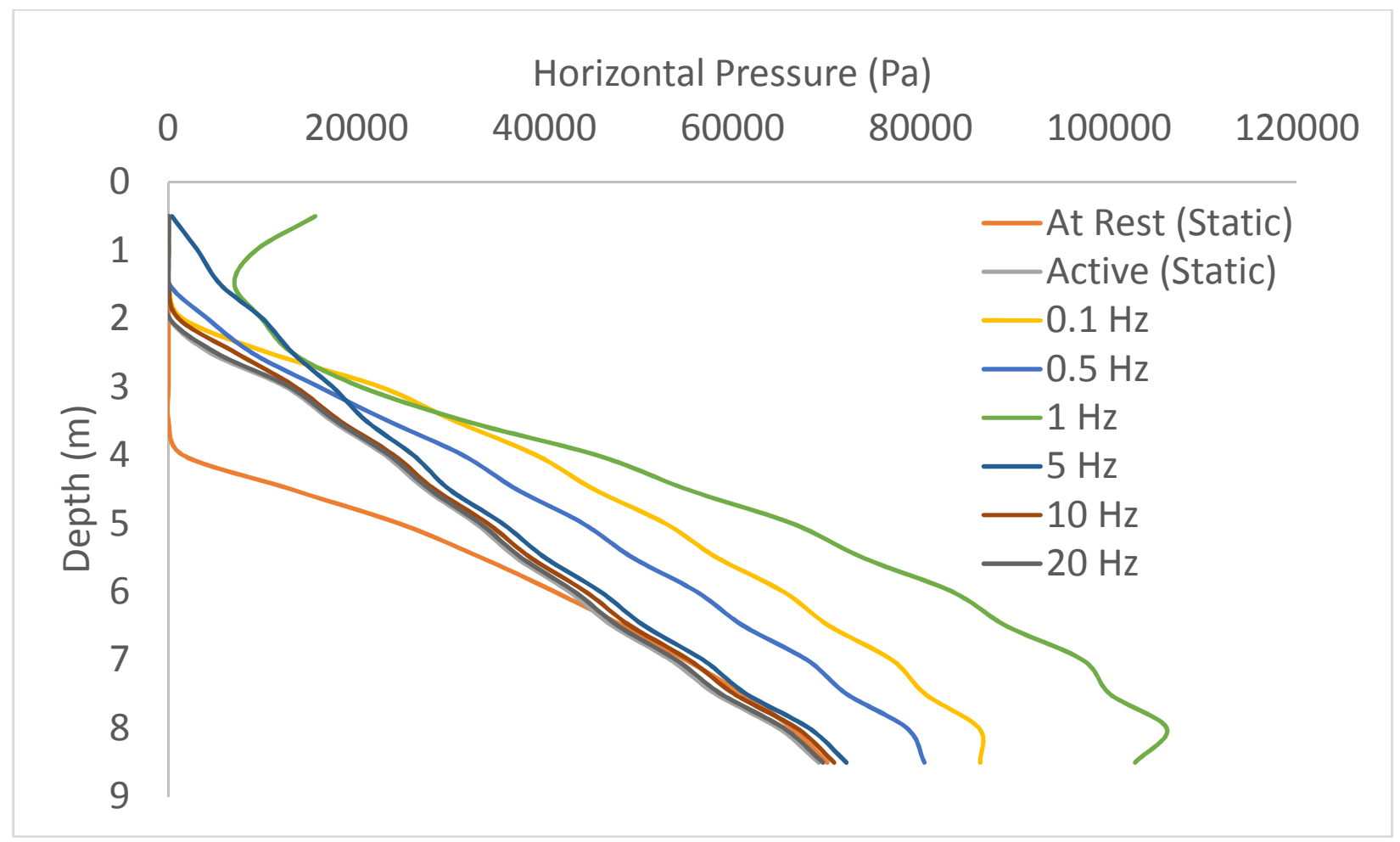

Figure 20: Cantilever Wall Maximum Pressures Observed at Each Frequency Sampled, Depth vs. Pressure, compared to At Rest \& Static Active Conditions

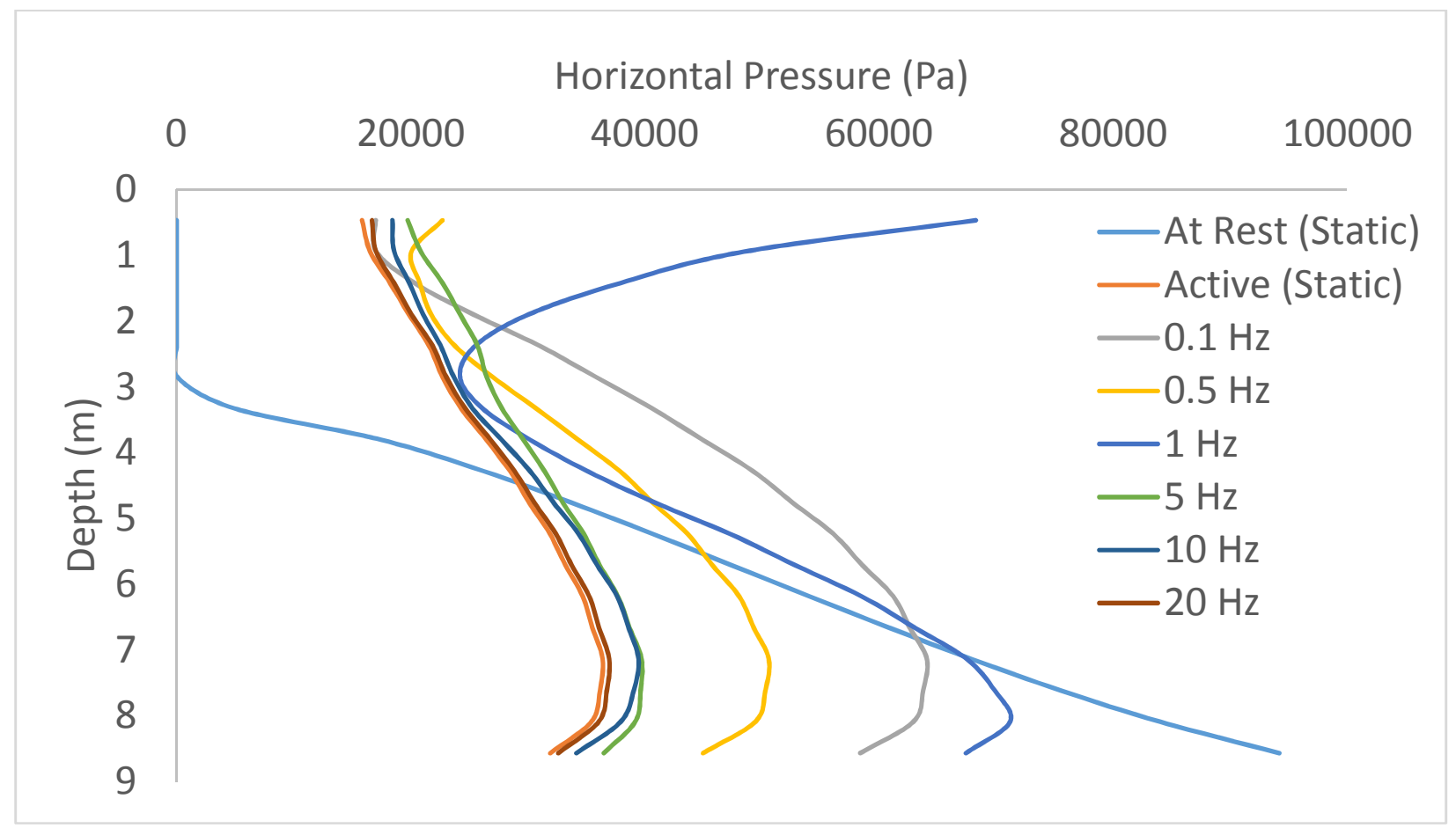

Figure 21: Gravity Wall Maximum Pressures Observed at Each Frequency Sampled, Depth vs. Pressure, compared to At Rest \& Static Active Conditions 


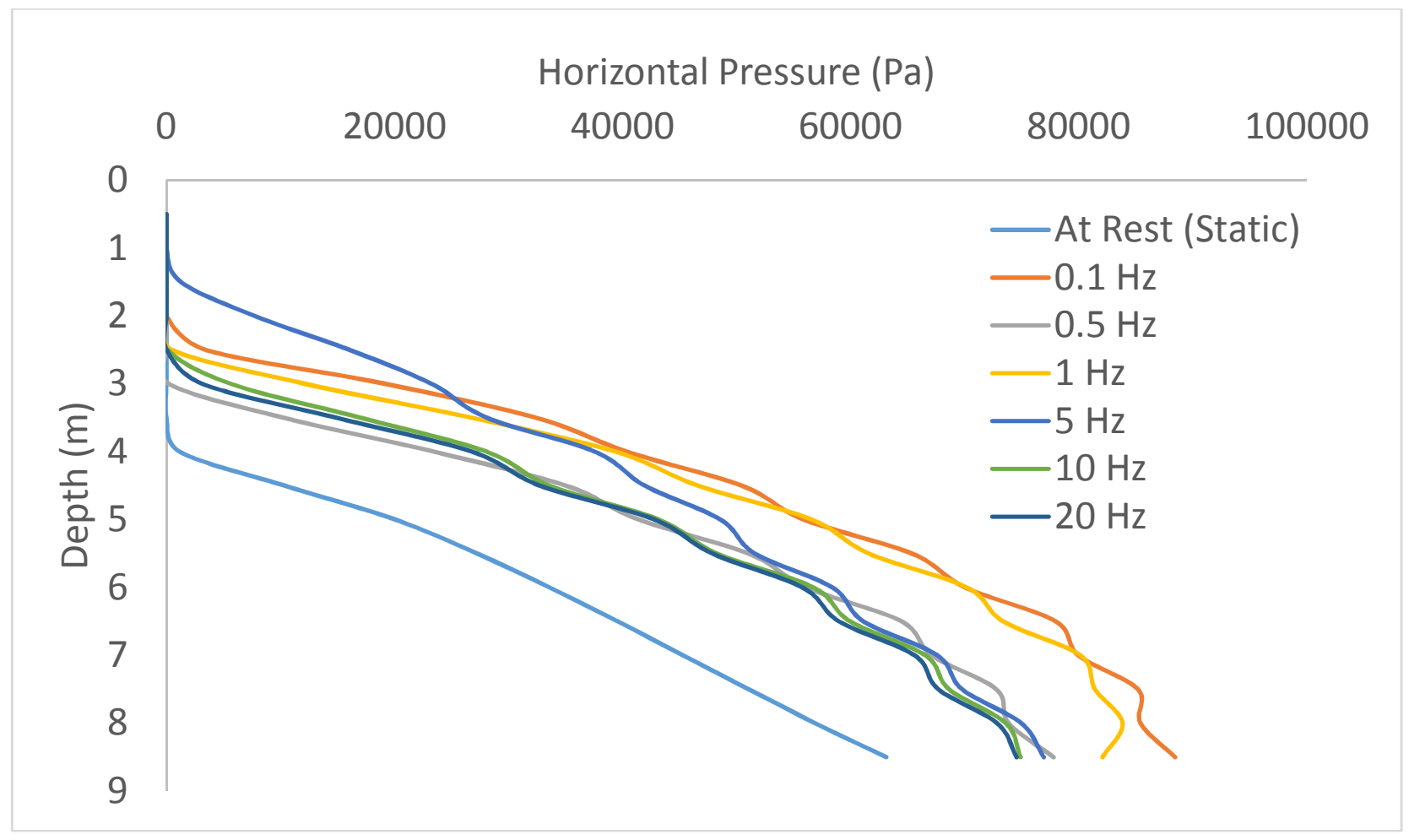

Figure 22: Basement Wall Maximum Pressures Observed at Each Frequency Sampled, Depth vs. Pressure, compared to At Rest Conditions 


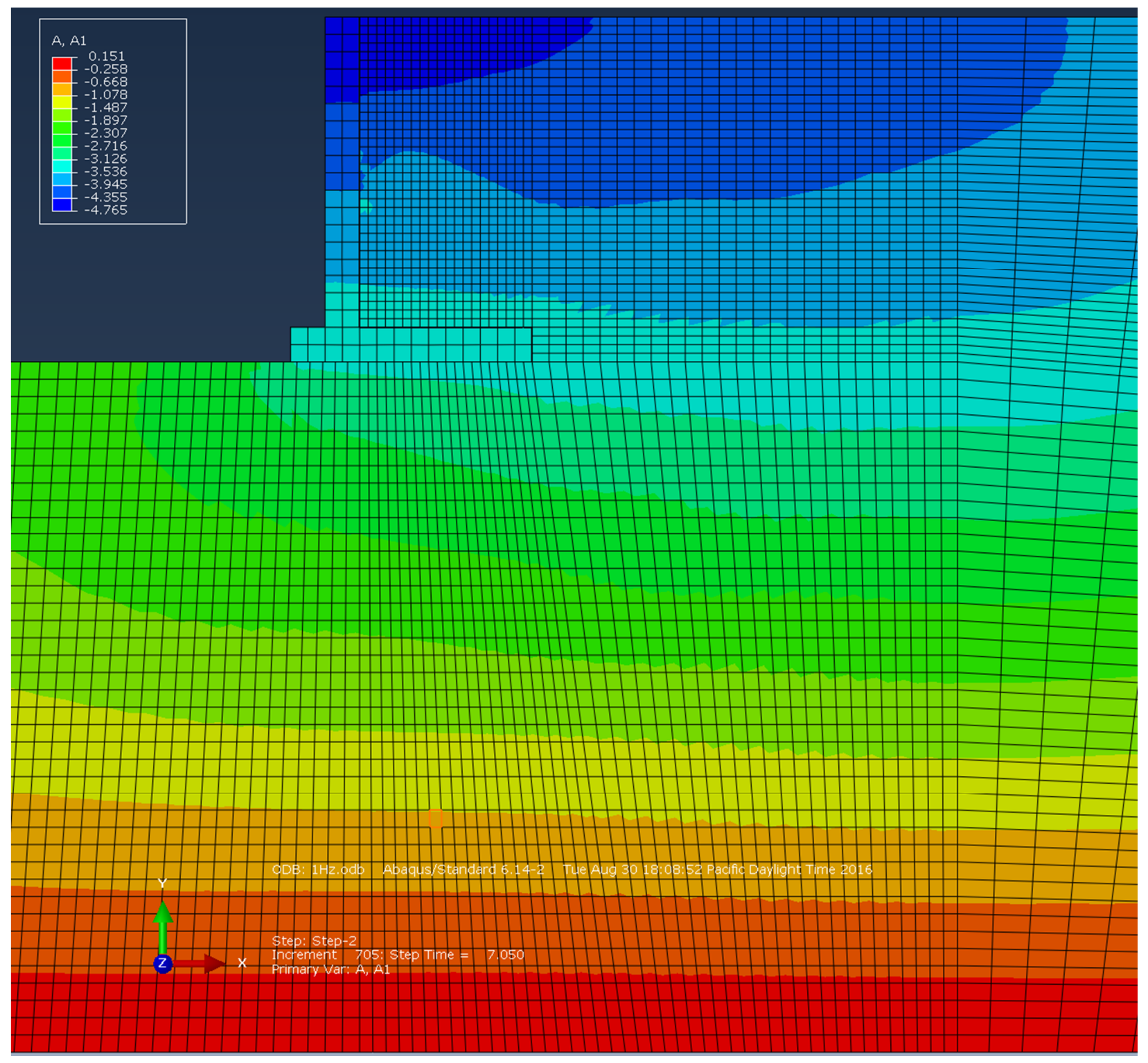

Figure 23: Color Contour of Maximum Horizontal Accelerations at Cantilever Wall at $1 \mathrm{~Hz}$ Driving Frequency, Values in units of $g=9.81 \mathrm{~m} / \mathrm{s}^{2}$ 


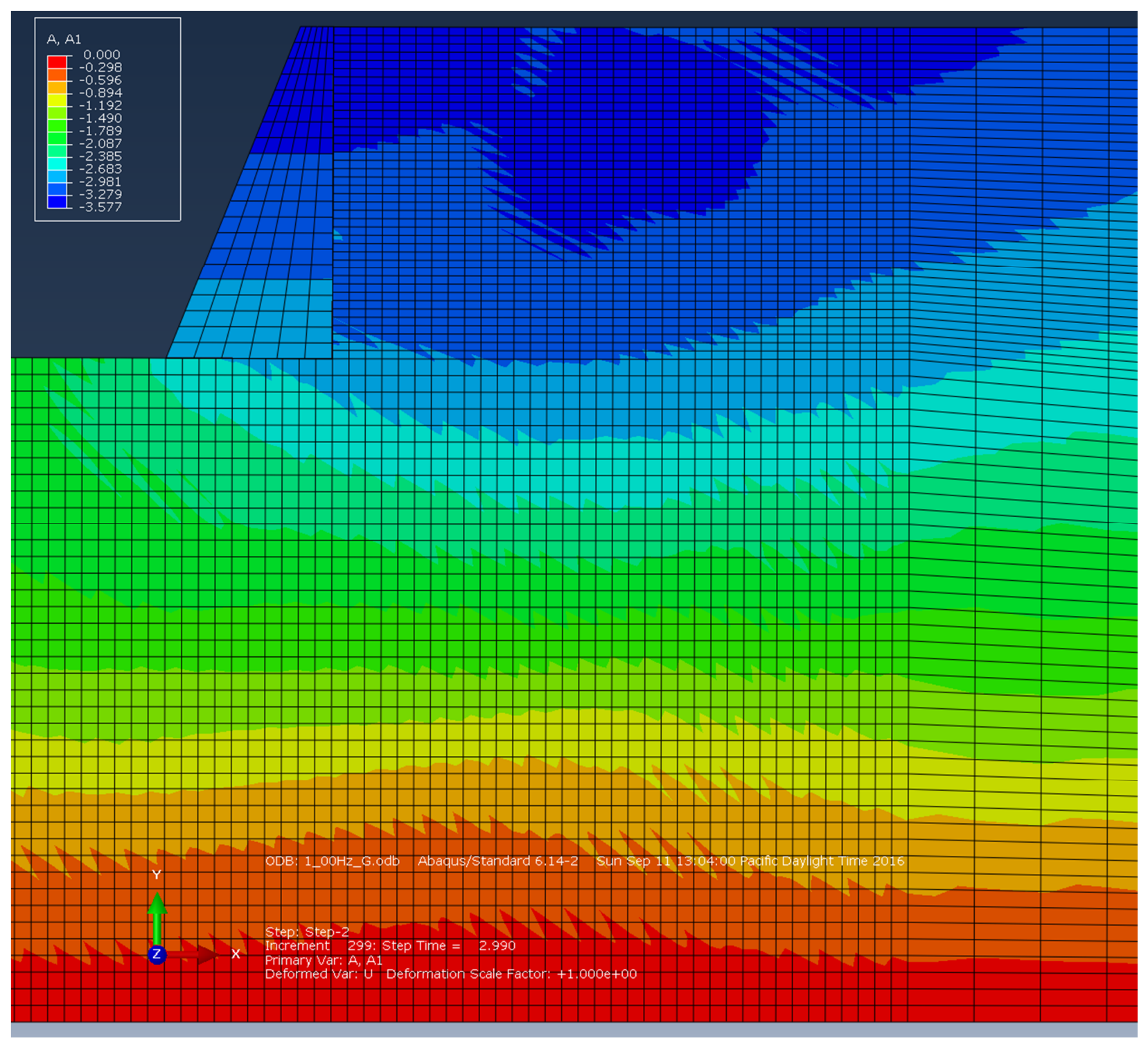

Figure 24: Color Contour of Maximum Horizontal Accelerations at Gravity Wall at $1 \mathrm{~Hz}$ Driving Frequency, Values in units of $\mathrm{g}=9.81 \mathrm{~m} / \mathrm{s}^{2}$ 


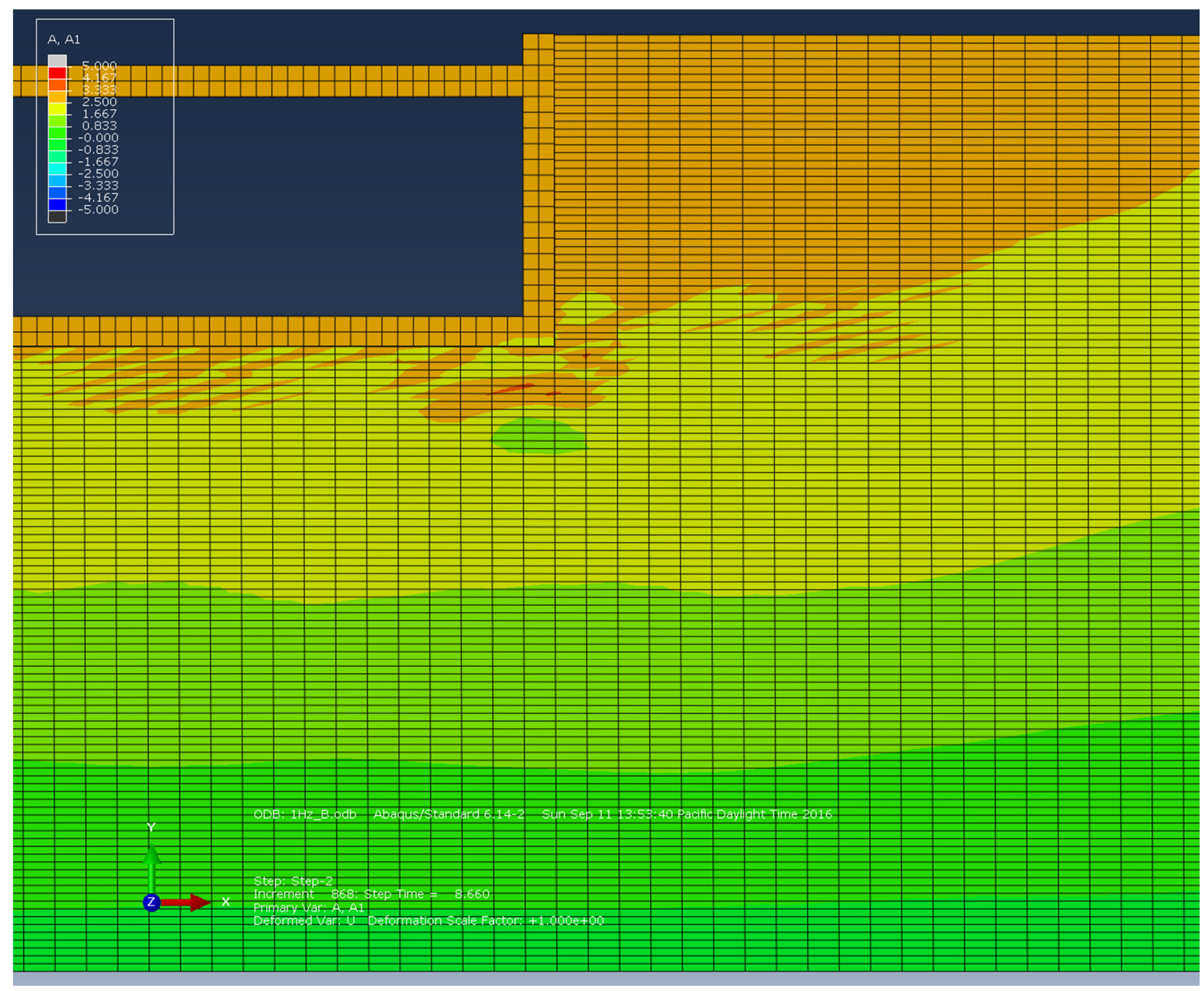

Figure 25: Basement Color Contour of Maximum Horizontal Accelerations at Basement Wall at $1 \mathrm{~Hz}$ Driving Frequency, Values in units of $\mathrm{g}=9.81 \mathrm{~m} / \mathrm{s}^{2}$ 


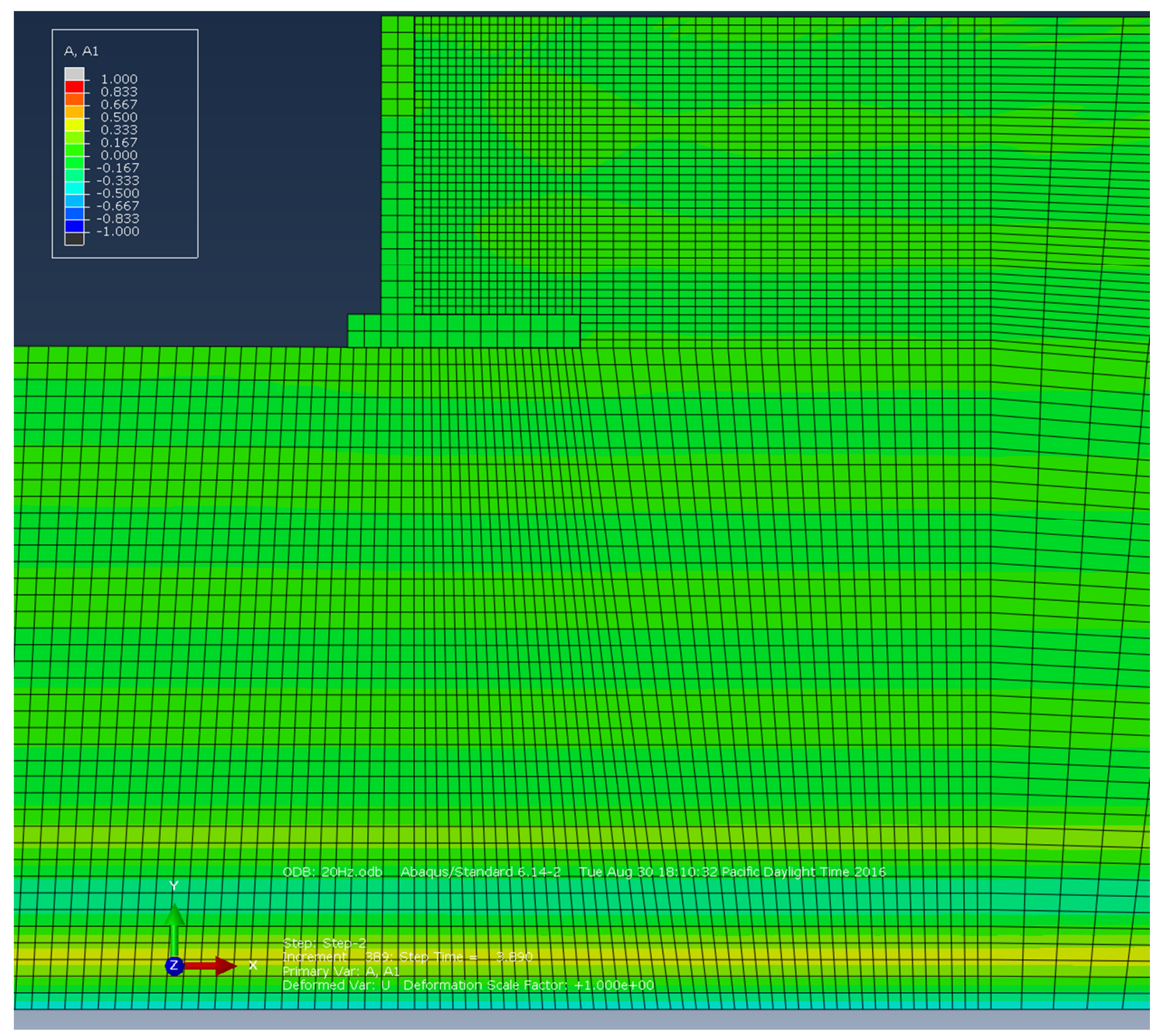

Figure 26: Color Contour of Minimum Horizontal Accelerations at Cantilever Wall at $20 \mathrm{~Hz}$ Driving Frequency (Other Cases Similar), Values in units of $g=9.81 \mathrm{~m} / \mathrm{s}^{2}$

\subsection{Discussion of Results}

Figures 17-19 show each walls maximum, enveloped, dynamic pressure for each frequency sampled, compared with maximum calculated dynamic pressure using M-O Theory. The values used for the M-O Theory calculation are identical to the parameters used in the model setup for each wall. The angle of wall friction, $\delta$, was assumed to be 0.5 the angle of internal friction for 
the soil, $\varphi$. This parameter is used in M-O theory; however, it is not explicitly used as an input for the ABAQUS model.

Each of the three walls exhibited a maximum dynamic pressure increment at a driving frequency of $1.0 \mathrm{~Hz}$. This frequency appears to correspond with a $1^{\text {st }}$ mode of resonance within the soil, out of phase with each wall. It should be noted that although the soil does not necessarily exhibit perfect resonance at $1.0 \mathrm{~Hz}$, near resonance of the soil still shows a significant amplification of accelerations at the wall face(s), relative to the driving frequency at the base of the model. At higher frequencies, the total pressure experienced during the dynamic step of the analyses decreased greatly, conforming closely to the static active pressure cases, or at-rest conditions for the case of the basement wall. The visualization of the horizontal accelerations at $20 \mathrm{~Hz}$ for each wall shows clearly the damping out of the driving frequency as it travels up through the soil. These results indicate an 'in-phase' response of the soil and the wall at higher frequencies.

Figures 17-19 show a dynamic earth pressure increment higher than that of M-O theory for multiple frequencies, for each wall case, as well as numerous frequencies where the dynamic pressure is exhibited to be lower than M-O. It should be noted that for the gravity and basement walls, $0.1 \mathrm{~Hz} \& 1 \mathrm{~Hz}$ frequencies show high dynamic pressure increments, indicative of an out of phase response. This only appears to occur at $1 \mathrm{~Hz}$ for the cantilever retaining wall, with the dynamic pressure at $0.1 \mathrm{~Hz}$ being approximately half, and lower than calculated by M-O theory.

Some inherent problems with modeling the soil through finite element analyses are apparent in the results. It can be seen in figures 20-22 that the at rest and static-active conditions show zero pressure on each wall, extending down to a depth of up to (4) meters for the former. This can be attributed to perfect stacking of the mesh under gravity loading, where the friction angle of the soil is able to 'restrain' it from producing horizontal pressures, where the surcharge 
loading from soil above is not high enough to do so. However, the gravity and cantilever walls both exhibit static-active pressures that are lower or near equal to those during at rest conditions. This indicates that the constitutive models and the sequencing of boundary conditions has achieved realistic characteristics, regardless of the shortcomings of the model. The basement wall did not exhibit any change in static pressures from at-rest conditions while under the same model set up, indicating correct response of a rigid basement wall subjected to lateral earth pressure.

\subsection{Graphical Comparison to Existing Research}

The results of this study are compared with the aforementioned existing work in this section. With any comparison to existing results, one of the most important factors to consider is normalizing the data between studies. It is understood and acknowledged that this study uses artificial ground motions, not pre-recorded input from a specific one. Due to this, it would be difficult to make an exact comparison between the work of Ostadan et al, and Sitar et al. However, because the caveat of this study is to provide a generalized explanation for the results of both the former and the latter, this does not impede the overall goal.

The following figures show the comparison of dynamic pressure increment between the results of this study, the work of Ostadan (2005), Al Atik \& Sitar (2009), and Brandenberg et al. (2015). Due to the difference of the input base accelerations used in each study, the results have been normalized against the PGA used. For reference, this study used a 0.1g PGA, compared to 0.3g for Ostadan et al, and 0.65g for the work of Al-Atik \& Sitar et al. (Brandenberg, 2015). Brandenberg results are scaled to the same PGA as Ostadan or Sitar, depending on the ground motion used. The work of Ostadan et al. is compared to the maximum and minimum values obtained for the basement wall case of this study, and the work of Sitar is compared with the cantilever wall. The maximum and minimum pressures for this study are those occurring at the 
driving frequencies listed in the preceding sections. The values obtained for the existing results of Brandenberg, Sitar, \& Ostadan have been visually approximated from the data shown in figure 6. As previously stated, because this comparison is to compare generalized explanations of different results, a visual approximation of the data is sufficient to draw the intended conclusions.

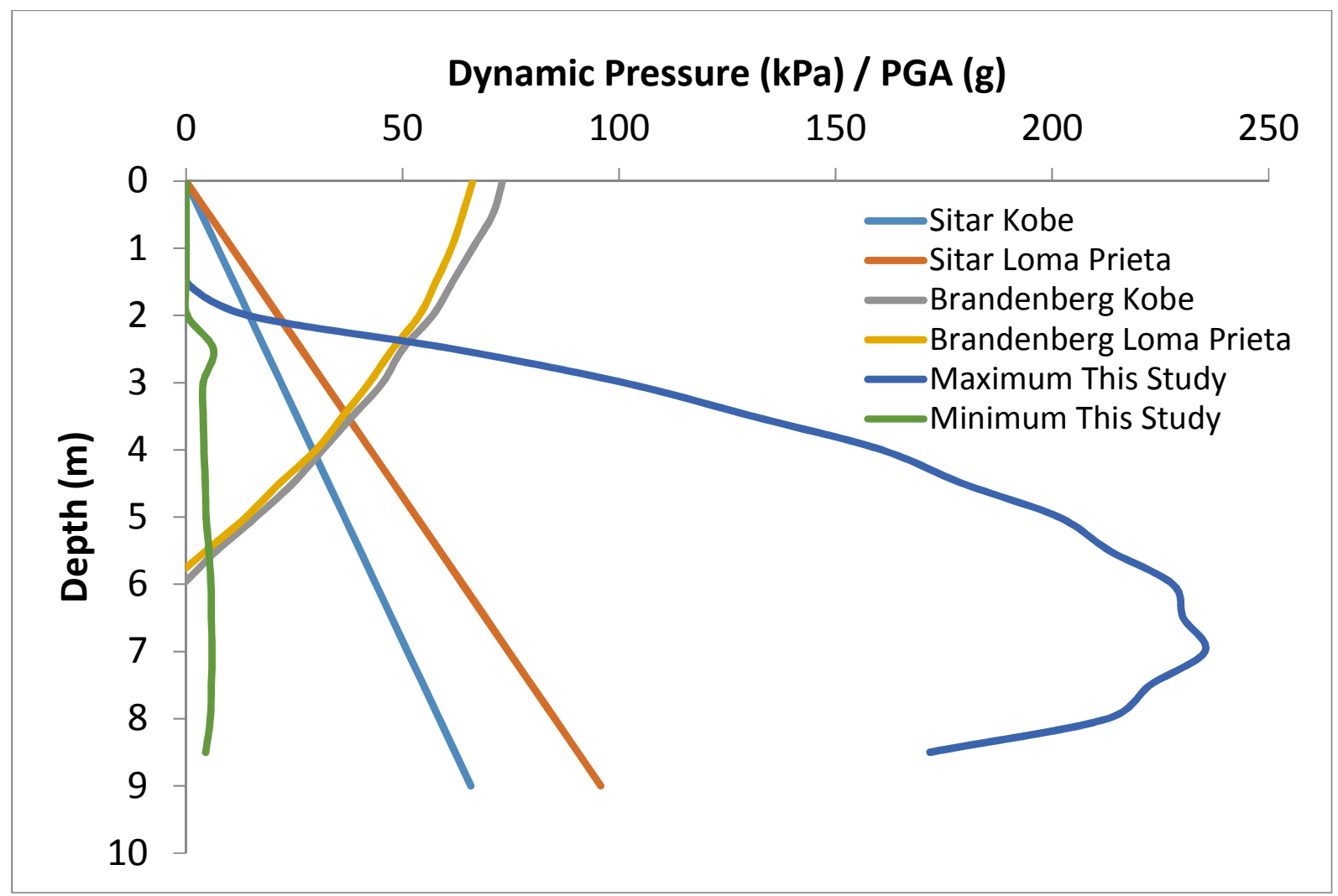

Figure 27: Comparison of Al Atik \& Sitar (2009) \& Brandenberg et al. (2015) with Cantilever Wall Results for This study 


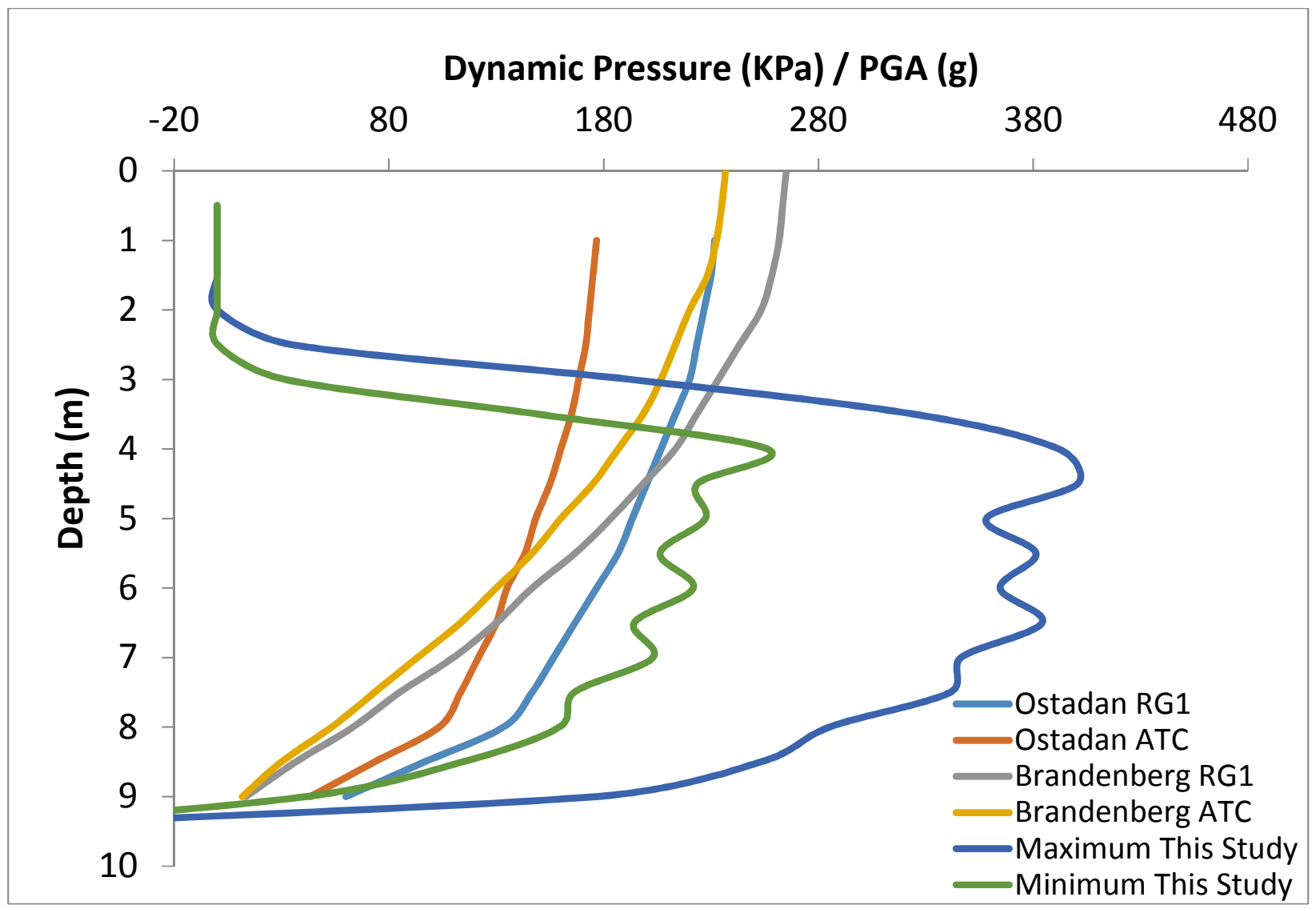

Figure 28: Comparison of Al Atik \& Sitar (2009) \& Brandenberg et al. (2015) with Basement Wall Results for This study

Figure 27 shows a significant difference between the maximum and minimum dynamic pressures of this study compared with the existing studies. There is approximately a $317 \%$ increase in dynamic pressure at a depth of 7 meters between the Sitar results for Loma Prieta, and the maximum pressure of this study, the largest positive difference. Conversely, the largest negative difference between existing research and this study occurred at a depth of 8 meters, where the same Sitar results for the Loma Prieta input motion were over $2000 \%$ larger. Additionally, the overall dynamic pressure profile of this study more closely resembles that of Sitar et al. (2009) than the results of Brandenberg et al. (2015). 
Figure 28 shows a smaller variation in normalized dynamic pressure increment between existing research and this study, as well as the minimum dynamic pressure being larger than the maximum dynamic pressure observed by either Ostadan (2005) or Brandenberg et al. (2015). 


\subsection{Overview}

\section{CHAPTER 5 CONCLUSIONS}

This study was performed to attempt to explain the diverging work of Ostadan, and AlAtik \& Sitar, with regards to M-O theory being suitable to explain seismic earth pressures on retaining walls. The work of the study aims to not create exact physical conditions as they would occur in reality, but impose realistic constitutive modeling and boundary conditions, to capture a spectrum of different conclusions, which can then be further refined in future studies for a particular case. The different driving frequencies used are not characteristic of a single ground motion, or of many different ones for that matter. Additionally, the low amplitude used for each driving frequency $(0.1 \mathrm{~g})$ is not expected to cause plastic damage or failure of the models. Instead, these parameters are used to show how under a single ground motion, with any amplitude, the frequency of the base acceleration can induce different conditions on the SSI spectrum, and these individual 'snapshots' can be recreated to encapsulate the work of both Ostadan, and Al-Atik \& Sitar.

\subsection{Cantilever Wall}

The cantilever wall showed approximately a $30 \%$ increase in dynamic pressure during the $1 \mathrm{~Hz}$ driving frequency, at depths of around 4-7 m, over the values calculated using M-O theory. Additionally, while only the $5 \mathrm{~Hz}$ driving frequency produced a dynamic pressure higher than that expected using M-O theory at a depth of 2 meters, all driving frequencies showed an increase of pressure from static-active conditions, over their maximum enveloped values. These dynamic pressures, shown in figure 17, align with both the work of Sitar et al. and Ostadan et al. as shown in figure 6, where lower driving frequencies $(<1 \mathrm{~Hz})$ result in a large increase in pressures below depths of approximately 3 meters, while higher frequencies appear to show a larger increase in pressure at shallower depths of less than 3 meters. The pressures observed are considerably lower 
than those shown in figure 6, although this is to be expected with an amplitude of the driving frequency at only $0.1 \mathrm{~g}$.

The maximum difference between an observed in-phase response of the wall and soil, compared with the out of phase response is shown in figure 17, where $1 \mathrm{~Hz}$ represents the latter and $20 \mathrm{~Hz}$ represents the former.

\subsection{Gravity Wall}

The gravity wall showed lower dynamic-active pressure increases than the cantilever wall for the same conditions with one exception; at a $1 \mathrm{~Hz}$ driving frequency, there is a large spike in the pressure increment at a depth of 0.5 meters, visible in figure 18, approximately 20 times higher than M-O theory calculations. This appears to be indicative of separation of the wall and soil separation followed by making hard contact, akin to slamming against one another. This is the result of an out of phase response between the wall and the soil. While we would not expect to see deformation like this in reality with a low base acceleration amplitude of $0.1 \mathrm{~g}$, the results are similar for driving frequencies of 0.1 and $0.5 \mathrm{~Hz}$. These similar increases in dynamic active pressure towards the top of the gravity wall demonstrate that near or perfect out of phase response can greatly increase dynamic-active pressures.

Additionally, the dynamic-active pressures on the gravity wall were either at or below MO suggested conditions, shown in Figure 18, for depths greater than 2 meters. The exception is an approximate $12 \%$ increase in dynamic active pressure at a driving frequency of $0.5 \mathrm{~Hz}$ from 3 to 5 meters in depth. These results appear to be more in line with the work of Sitar et al. than those of the cantilever wall. 


\subsection{Basement Wall}

The basement wall showed large increases in dynamic pressures below depths of 3 meters, for many different driving frequencies of base ground acceleration. The highest of these is an approximate $200 \%$ increase over calculated $\mathrm{M}-\mathrm{O}$ values at a depth of 3 meters, visible in figure 19. Another caveat of note is the depth from 0 to 3 meters experiencing virtually no dynamic pressures on the basement wall for all different driving frequencies of base acceleration. This is comparable to the at rest conditions shown for the basement wall with respect to depth in figure 22. This indicates that active pressures have not been mobilized for the basement wall, and that the seismic pressures are instead dynamic-passive conditions. It is well known that M-O theory relies on the assumption that the wall deflects enough $(>0.01 \mathrm{x} \mathrm{H}$, where $\mathrm{H}$ is the height of the wall) to create active conditions. Because the basement wall is modeled as a rigid object, it is not able to deflect enough to mobilize active conditions. This is also clearly shown in the comparison between at-rest and active conditions for the static case. The cantilever and gravity walls show a clear distinction between the two, while the basement wall does not.

The dynamic lateral pressure vs depth results for the basement wall shown in figure 19 are very similar in overall geometry to the results of Wood et al., shown in figure 3. Although the lateral dynamic pressures towards the top of the basement wall were found negligible, again, this can be attributed to mesh stacking of the soil, and maintaining elasticity, preventing an increase in lateral pressures, as described in the previous results section. Aside from this, the dynamic pressure profile of the basement wall in figure 19 again shows a clear contrast between different driving frequencies. This difference is highest at a depth of approximately 4 meters, with over $175 \%$ increase between the $10 \mathrm{~Hz}$ and $1 \mathrm{~Hz}$ driving frequencies. Additionally, the $0.1 \mathrm{~Hz}$ frequency did not result in high dynamic lateral pressures. This deviates from the cantilever and 
gravity wall results. One explanation for this is because of the higher relative rigidity of the basement wall compared with the other wall systems, the out of phase response of the soil and wall occurs over a much smaller range of frequencies.

\subsection{Comparison to Existing Research}

The results of this study take an encompassing approach to validate both the work of Ostadan \& Sitar et al. SSI can be used to explain how different seismic earth pressures can be expected on a given retaining wall or basement wall system. M-O theory incorporates materialistic properties, i.e. unit weight, friction angle, etc. as well as dynamic properties such as PGA. Both Ostadan \& Sitar et al. inherently define all of these properties in their results, however, do not factor in relative base acceleration frequencies with respect to time in their solutions. This study adds an additional element to the calculation of lateral earth pressures, thus bridging the gap in results of the former and the latter.

Figure 4 plots the change in dynamic pressure coefficient with respect to the amplitude of PGA, and cites numerous recorded ground motions (Sitar et al. 2013) to plot a trend line of these two parameters. While this supports the notion of Sitar that M-O theory is overly conservative, again, frequency is left out of this approach. The same can be said for the work of Ostadan et al. in Figure 3. Using ground motions and a static wall height, or type, significantly greater than MO pressures are plotted with respect to height. Brandenberg et al. distinguishes between both of these solutions in Figure 6, but as previously stated, does not offer validity of one solution over another.

Figures 27 and 28 show the most direct comparison to the existing work of Ostadan et al. and Sitar et al. It is clearly shown that the normalized data supports the conclusions of the former and the latter, depending on whether an in phase or out of phase response occurs. These figures, 
however, should not imply an exact difference in dynamic pressure increment. This is because they are normalized against one another using dynamic pressure divided by the PGA used for each study. This implies that PGA and dynamic pressure increment follow a specific linear relationship to one another for values up to at least $0.65 \mathrm{~g}$. Figure 4 shows that this is not always the case. Therefore, while this discounts the ability to exactly normalize the data with respect to PGA, it does not result in an order of magnitude of difference.

The base accelerations used in this study contrast the work of Ostadan et al. \& Sitar et al., in the sense that they are a sinusoidal wave, and not a recorded motion of a previous shaking event. Although a perfect sinusoidal wave base acceleration versus time curve is all but impossible in reality, this does not discount the validity of the results of this study. This is because any given seismic event will have multiple base acceleration values, occurring at different times with respect to one another. If an infinite number of ground motions were produced from a single site, these would ultimately lead to any possible out of phase response between a given retaining structure and the soil, should one be able to occur.

\subsection{Recommendations for Future State of Practice}

The results of this study, as previously stated, show the important role that SSI has in determining the lateral seismic pressures on a retaining or basement wall. As this study focused on an encompassing, theoretical approach to validating the work of both Sitar et al. \& Ostadan et al., it does not outline a specific past or future ground shaking event. However, the results here can serve as an outline for determining the relative importance of different factors in future design. It can be argued that any portion of the acceleration time history of this study can occur during a given shaking event. It would thus be unreasonable to take an un-conservative design approach based on these findings. If a retaining wall system has the possibility of responding out of phase 
with the surrounding free field during a seismic event, this would dictate a more conservative design approach. Conversely, if out of phase response is not to be expected based on the system design and surrounding free field, a less conservative design approach can be taken without a compromise in performance.

Special consideration should be given to calculating modes of resonance as they pertain to walls, as well as the soils they are constructed upon. Additionally, well measured and identified faults can provide an additional layer of information; determining probabilities of base acceleration frequencies. Site effects should also be considered. It is inherent that different frequencies will induce different levels of in phase and out of phase response for the same wall system, with different free field depths, soil compositions, etc. The results of this study indicate that retaining walls should be examined on a case-by-case basis for seismic design. M-O theory can be used to encompass a wide array of conditions, while being at least marginally conservative, though for projects where out-of-phase conditions can be predicted, a more robust approach should be used.

While cantilever and gravity retaining walls are shown to be heavily dependent on driving frequency of ground motion to produce seismic earth pressures, basement walls appear to be less sensitive to this. M-O theory should be carefully considered, if not discarded, regarding any retaining wall system that is not flexible enough to mobilize dynamic-active conditions, i.e. a basement wall braced against flexure or displacement. Figure 19 clearly shows that for all of the driving acceleration frequencies tested, higher than M-O pressures were achieved. This coincides with the results of Wood et al. and Ostadan et al. in that M-O theory is grossly un-conservative for a retaining wall system encountering dynamic-passive conditions. 


\subsection{Recommendations for Future Research}

While this study was intended to capture a variety of conditions to explain diverging opinions of Ostadan and Al-Atik and Sitar, or in a broader sense, the validity of M-O Theory for determining seismic earth pressures, large breadth of the research allows for future work to examine more in-depth conditions.

\subsubsection{Variations in Ground motion \& Boundary Conditions}

Boundary conditions were simplified in this study to reduce computational time, because their accurate modeling to realistic conditions was the main focus, and nothing further. In reality, conditions such as the ones used in this study simply don't exist, i.e. a completely flat boundary condition with the soil/rock interface, which precludes any wave focusing effects, or others which may contribute to an amplification or de-amplification of seismic pressures on a retaining wall system. Future studies wishing to add to this area of the problem could study the changes in lateral earth pressures due to different base conditions in the model, and their relevance when factored in to the different 'snapshots' of the SSI spectrum captured here.

Additionally, simplifications were made to the ground motion of the study. It is assumed that no ground motion in reality will have an acceleration vs. time plot of a perfect sine wave, which does not matter as it pertains to the conclusions here. Because the focus of this study was to capture different 'snapshots' of the SSI spectrum, and not necessarily model a case study, a specific

ground motion did not need to be analyzed. However, in this study the ground motion was fully relegated to the lateral direction, with no vertical component. Future work could be done to investigate the effects of vertical and horizontal acceleration occurring simultaneously, and any effects this may have on the lateral pressures of retaining or basement walls. 
Because the walls themselves were not the focus of this study, i.e., internal stresses in the walls, or detailed materialistic properties were not investigated, there is another inherent simplification with respect to reality. A possible future study could compare relative rigidities of different wall systems, and how different elastic or inelastic deflections of the wall can contribute to an increase or decrease of lateral earth pressures. One instance of this could be to compare reinforced concrete retaining walls with driven piles, timber walls, or a geo-synthetic textile grid type of wall.

Because this study was focused on capturing different instances of the SSI spectrum, and not necessarily plastic strains or failure of the retaining or basement walls, the base accelerations were limited to a value of $0.1 \mathrm{~g}$ in amplitude. For earthquakes to cause noticeable damage the amplitude of the base ground motion is usually higher than $0.1 \mathrm{~g}$, special and unique cases aside. Future studies could explore increasing amplitude and its relationship to lateral seismic earth pressures, and whether the correlation shown in figure 4 of free field PGA to $\Delta \mathrm{K}_{\mathrm{ae}}$ described by the work of Al-Atik \& Sitar is realistic of all driving frequencies, or limited lower range values.

\subsection{Summarization of Study \& Accomplishment of Goals}

The goal of this study was to explain diverging opinions of Ostadan et al. \& Sitar et al., the former stating that $\mathrm{M}-\mathrm{O}$ theory is grossly un-conservative as an approach to determining seismic retaining wall pressures, and the latter stating the opposite. This study does not intend to discredit the research already done on the topic, but instead more accurately capture 'snapshots' of when each condition is more prevalent, and the role that SSI plays in determining seismic earth pressures on retaining structures.

The resulting research and testing for this study included developing a 2-D finite element model using ABAQUS software, using the Drucker-Prager constitutive model in addition to 
elasticity parameters and non-reflecting boundary conditions. This allowed for an accurate approach to simulate realistic conditions of both the free field, and near field response of three different retaining systems, over a range of different ground motion frequencies, to capture the 'snapshots' described.

Different driving frequencies of base acceleration, input as sinusoidal wave motions, were determined to heavily influence the dynamic pressures on each of the three wall cases analyzed, and were more likely to increase or decrease dynamic pressures where the wall was able to mobilize active conditions. M-O theory was found to be a reasonable design procedure for instances where the soil was not exhibiting first mode resonance, and was able to move in phase with the retaining wall system(s). This was not the case however, for the basement wall system, where passive dynamic conditions created much higher than M-O pressures, regardless of the soil exhibiting resonance or not.

This study presents a conclusion that future retaining walls should be designed on a caseby-case basis for dynamic pressures, dependent on an array of different conditions. If it can be determined that a first mode response of the soil, out of phase with the wall system can be avoided, M-O theory serves as an accurate upper limit estimate for calculating seismic earth pressures.

We believe that the results of this study validate the original hypothesis that SSI effects contribute greatly to the determination of seismic earth pressures. Existing research has captured different instances of this interaction (Ostadan et al., Sitar et al., Brandenberg et al.) but not taken an encompassing approach to the problem. This study should serve as a stepping point to further refining the importance of SSI on retaining structures, and how design can be best optimized to fit a wide array of conditions 


\section{WORKS CITED}

ABAQUS (2014) ‘ABAQUS Documentation’, Dassault Systèmes, Providence, RI, USA.

Al Atik, L., and Sitar, N. (2009). "Experimental and analytical study of the seismic performance of retaining structures." Rep. No. Pacific Engineering Earthquake Engineering Research (PEER)-2008/104, PEER Center, Univ. of California, Berkeley, CA.

Bielak, J. (1975). ' Dynamic behavior of structures with embedded foundations.' J. Earthquake Engrg. Struct. Dyn., 3(3), 259-274.

Brandenberg, Scott J., George Mylonakis, and Jonathan P. Stewart. "Kinematic Framework for Evaluating Seismic Earth Pressures on Retaining Walls." J. Geotech. Geoenviron. Eng. Journal of Geotechnical and Geoenvironmental Engineering 141.7 (2015): n. pag. Ascelibrary.org. Web. Aug.-Sept. 2015.

Coulomb C.A. Essai sur une application des regles des maximis et minimis a quelques problemes de statique relatifs a l'architecture. Memoires de l'Academie Royale pres Divers Savants, (1776) 7 .

De Weck, Olivier, and Il Yong Kim. 16.810_L4_CAE. N.p.: Massachusetts Institute of Technology, 12 Jan. 2004. PPT.

Drucker, D. C. and Prager, W. (1952). Soil mechanics and plastic analysis for limit design. Quarterly of Applied Mathematics, vol. 10, no. 2, pp. 157-165.

Gazetas, G, Psarropoulos, PN, Anastasopoulos, I. and Gerolymos, N. (2004). "Seismic Behaviour of Flexible Retaining Systems Subjected to Short-Duration Moderately Strong Excitation," Soil Dynamics and Earthquake Engineering, (24), 537-550

Hall, Garrett and Kasper, Eric. "Discussion of ABAQUS Inputs and Characteristics." Personal Discussion. 2016.

Helwany, S. (2007) Elasticity and Plasticity, in Applied Soil Mechanics: with ABAQUS Applications, John Wiley \& Sons, Inc., Hoboken, NJ, USA. doi: 10.1002/9780470168097.ch2

Ju, Shen-Haw, and Sheng-Huoo Ni. "Determining Rayleigh Damping Parameters of Soils for Finite Element Analysis." International Journal for Numerical and Analytical Methods in Geomechanics 31.10 (2007): 1239-255. Web.

Lew, M., Sitar, N., Al-Atik, L., Pourzanjani, M. and Hudson, M.B. (2010b). "Seismic Earth Pressures on Deep Building Basements." Structural Engineers Association of California, Proceedings of the Annual Convention, 2010. 
Luco, J. E. (1980). 'Linear soil-structure interaction.'” Soil-structure interaction: The status of current analysis methods and research, J. J. Johnson, ed., Rep. No. NUREG/CR-1780 and UCRL-53011, U.S. Nu- clear Regulatory Commission, Washington, D.C. and Lawrence Livermore Laboratory, Livermore, Calif.

Matinmanesh, H., and Mohammed Saleh Asheghabadi. "Seismic Analysis on Soil-Structure Interaction of Buildings over Sandy Soil." ResearchGate. Elsevier Ltd., 2011. Web. Aug.-Sept. 2015.

Mikola, R. G., \& Sitar, N. (2013). Seismic Earth Pressures on Retaining Structures in Cohesionless Soils.

Miranda, E. and 'Bertero, V. (1994) "Evaluation of strength reduction factors of earthquake-resistant design," Earthq. Spectra 10(2), 357-379.

Mononobe, N, and Matsuo M. "On the Determination of Earth Pressures during Earthquakes," Proceedings, World Engineering Congress, Vol. 9, 179-187, 1929. Okabe S. "General Theory of Earth Pressure," Journal of the Japanese Society of Civil Engineers, Tokyo, Japan, Vol. 12 , No. 1, 1926.

Mylonakis, George and Gazetas, George (2000) 'Seismic Soil-Structure Interaction: Beneficial or Detrimental?', Journal of Earthquake Engineering, 4: 3, 277 - 301

Newmark, N. M. and Hall, W. J. (1973) (Seismic design criteria for nuclear reactor facilities," Report No. 46, Building Practices for Disaster Mitigation National Bureau of - Standards,- US Department of Commerce, pp. 209-236

"Online Help." Table of Ultimate Friction Factors for Dissimilar Materials | Influence of Friction between Soil and Back of the Structure | GEO5 | Online Help. N.p., n.d. Web. 2016. <http://www.finesoftware.eu/help/geo5/en/table-of-ultimate-friction-factors-fordissimilar-materials-01/>.

Ostadan, F. (2005). "Seismic soil pressure for building walls-An updated approach." Soil Dyn. Earthquake Eng., 25(7-10), 785-793.

Popescu, Radu. "Discussion of Drucker-Prager and Mohr-Coulomb Constitutive Models." Personal Discussion. 2016.

Rahgozar, Mohammed Ali. Seismic Soil-Structure Interaction Analysis of Structural Base Shear Amplification. Thesis. Carleton University, 1993. N.p.: n.p., n.d. Print.

Roesset, J. M. (1980). “A review of soil-structure interaction.' Soil- structure interaction: The status of current analysis methods and re-search, J. J. Johnson, ed., Rep. No. NUREG/CR-1780 and UCRL- 53011, U.S. Nuclear Regulatory Commission, Washington, D.C. and Lawrence Livermore Laboratory, Washington, D.C. 
Seed, HB, and Whitman, RV. "Design of Earth Retaining Structures for Dynamic Loads," ASCE Specialty Conference, Lateral Stresses in the Ground and Design of Earth Retaining Structures, Cornell Univ., Ithaca, New York, 103-147, 1970

Stewart, J. P., Fenves, G. L., and Seed, R. B. (1999). "Seismic soil- structure interaction in buildings. I: Analytical methods.” J. Geotech. Engrg., ASCE, 125(1), 26-37.

Stewart, J. P., Seed, R. B., and Fenves, G. L. (1999). "'Seismic soil- structure interaction in buildings. II: Empirical results.” J. Geotech. Engrg., ASCE, 125(1), 38-48.

Tekeste, M. Z., R. L. Raper, E. W. Tollner, and T. R. Way. "Finite Element Analysis of Cone Penetration in Soil for Prediction of Hardpan Location." Transactions of the ASABE 50.1 (2007): 23-31. Web.

United States. Department of Commerce. National Institute of Standards and Technology. SoilStructure Interaction for Building Structures. N.p.: n.p., 2012. Print. NIST GCR 12-91721.

Upadhyay, Anurag, A. Murali Krishna, and K. D. Singh. "Behavior of Cantilever Retaining Walls Under Seismic Condition." 5th International Conference on Earthquake Geotechnical Engineering (2011): n. pag. Web.

Veletsos, A. S., and Nair, V. V. (1975). "Seismic interaction of structures on hysteretic foundations." J. Struct. Engrg., ASCE, 101(1), 109 - 129.

Wood, J.H. (1973). "Earthquake Induced Soil Pressures on Structures," PhD Thesis, California Institute of Technology, Pasadena, CA. 